\title{
Sangspruchdichtung
}

Gattungskonstitution und Gattungsinterferenzen im europäischen Kontext

Internationales Symposium Würzburg,

15.-18. Februar 2006

Herausgegeben von Dorothea Klein

zusammen mit Trude Ehlert und Elisabeth Schmid

Sonderdruck aus

ISBN 978-3-484-10808-0

Max Niemeyer Verlag

Tübingen 2007

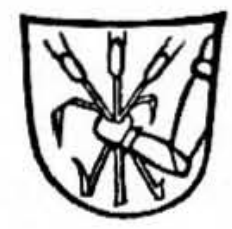




\section{Minne in den Sangspruchtönen Regenbogens \\ Eine Überschau in typologischer Absicht}

Die kurzen Angaben, die im $>$ Repertorium der Sangsprüche und Meisterlieder < dem Benutzer einen Eindruck vom Inhalt eines Sangspruchs oder Meisterlieds vermitteln, beginnen in den Regenbogen-Artikeln häufiger lapidar mit dem Schlagwort >Minnelied < oder >Liebeslied <. Die acht Fälle, die bereits die oberflächliche Durchsicht ans Licht bringt, ${ }^{1}$ geben Anlaß, genauer nachzufragen, in welcher Weise das Thema Minne in den Sangspruchtönen Regenbogens auftritt. Denn nachdem über Minne im Sangspruch bis zu Frauenlob inzwischen die Arbeit von EGIDI gut unterrichtet sowie speziell über die Minnesprüche und -lieder Frauenlobs und Heinrichs von Mügeln Beiträge von WACHINGER und KÖBELE beziehungsweise von STACKMANN und HUBER informieren, weiß man von dem wohl als Sangspruchdichter, aber doch kaum als Minnesänger bekannten Regenbogen landläufig wenig mehr als dies, $\mathrm{da} ß$ er schon frühzeitig als prominenter Frauenlob-Kontrahent wahrgenommen wurde und daß es ihm bis heute an einer kritischen Ausgabe fehlt. ${ }^{2}$ Vor allem aber wissen wir wenig über die Schicksale, die der

\footnotetext{
${ }^{1} \mathrm{Vgl}$. RSM, ${ }^{1} \mathrm{Regb} / 1 / 101$ und ${ }^{1} \mathrm{Regb} / 2 / 33 \mathrm{a}$ (Minnelied) bzw. ${ }^{1} \mathrm{Regb} / 1 / 544,{ }^{1} \mathrm{Regb} / 1 / 573$ und ${ }^{1}$ Regb/3/6 (Liebeslied) sowie 'Regb/1/553 ("Liebeslied mit Redeszenen «), ${ }^{1} \mathrm{Regb} / 1 / 562$ (»Liebesdialog $«$ ) und ${ }^{1}$ Regb/1/572 ("Liebeslied mit Lob und GruB der Geliebten $\ll)$.

${ }^{2}$ MARGRETH EGIDI: Höfische Liebe. Entwürfe der Sangspruchdichtung. Literarische Verfahrensweisen von Reinmar von Zweter bis Frauenlob. Heidelberg 2002 (GRMBeiheft 17); BURGHART WACHINGER: Hohe Minne um 1300. Zu den Liedern Frauenlobs und König Wenzels von Böhmen. Wolfram-Studien 10 (1988) 135-150; SUSANNE KÖBELE: Frauenlobs Lieder. Parameter einer literarhistorischen Standortbestimmung. Tübingen/Basel 2003 (Bibliotheca Germanica 43); KARL STACKMANN: Minne als Thema der Sangspruch- und Lieddichtung Heinrichs von Mügeln. In: $b i-$ ckelwort und wildiu mare. Festschrift für Eberhard Nellmann zum 65. Geburtstag. $\mathrm{Hg}$. von DorotheE LiNDEMANN u.a. Göppingen 1995 (GAG 618), S. 324-339 [wieder abgedruckt in ders.: Frauenlob, Heinrich von Mügeln und ihre Nachfolger. Hg. von Jens Haustein. Göttingen 2002, S. 143-157]; CHRISTOPH HuBER: Wege aus der Minneparadoxie. Zum Minnesang Heinrichs von Mügeln im Blick auf Konrad von Würzburg. In: Gattungen und Formen des europäischen Liedes vom 14. bis zum 16. Jahrhundert. Internationale Tagung vom 9. bis 12. Dezember 2001 in Münster. $\mathrm{Hg}$.
} 
höfischen Liebe in der meisterlichen Lieddichtung widerfahren, also in jener auf die noch weithin höfisch geprägte Sangspruchdichtung folgenden und zum Meistergesang in seiner institutionalisierten Form führenden Phase der Gattungsgeschichte zwischen der ersten Hälfte des 14. und dem ausgehenden 15 . Jahrhundert. ${ }^{3}$ In eben diese aber führt die Textüberlieferung in Tönen Regenbogens wie keine zweite in wünschenswerter Dichte und Streuung hinein. Sie findet ihren Ausgang

von MiCHAEl ZYWIETZ u.a. Münster u.a. 2005 (Studien und Texte zum Mittelalter und zur frühen Neuzeit 8), S. 89-109.

Forschungsstand zu Regenbogen faßt zusammen: FRIEDER SCHANZE: Regenbogen. In: ${ }^{2}$ VL, Bd. 7, Sp. 1077-1089. Seither zu ergänzen: REINHOLD SCHRÖDER: Der regenboge den vrouwenlop bestunt gelicher wer. Zu einigen Strophen der frühen Regenbogen-Überlieferung. In: Ja muz ich sunder riuwe sin. Fs. für Karl Stackmann zum 15. Februar 1990. Hg. von WolfGANG DiNKELACKER u.a. Göttingen 1990, S. 180-205; GISELA KORNRUMPF: Regenbogen. In: Literaturlexikon. Autoren und Werke deutscher Sprache. Hg. von WALTHER KILLY. Gütersloh/München 1988-93, Bd. 9, S. 332f.; DIETLIND GADE: Hoch in dem lufft wirt vns erzoegt ir wunder. Eine versifizierte ,Lucidarius s-Passage in Regenbogens Langem Ton. PBB 123 (2001) 230-252. Von Gisela Kornrumpf ist ferner seit längerem ein Beitrag zu den Fürstenpreissprüchen und Totenklagen Regenbogens aus der Handschrift Berlin, SBB-PK, Grimm-Nachlaß 132,13, angekündigt. Für einzelne Strophen, Lieder und Töne sind mehrere Arbeiten der letzten Jahre von Fall zu Fall ergiebig: JOHANNES RETTELBACH: Variation - Derivation - Imitation. Untersuchungen zu den Tönen der Sangspruchdichter und Meistersinger. Tübingen 1993 (Frühe Neuzeit 14); ELISABETH WUNDERLE: Die Sammlung von Meisterliedern in der Heidelberger Handschrift cpg 680. Edition und Kommentar. Göppingen 1993 (GAG 584); ANETTE VOLFING: The authorship of John the Evangelist as presented in medieval German sermons and Meisterlieder. Oxford German Studies 23 (1994) 1-44, hier S. 18-44; ULRIKE-MARIANNE SCHULZ: Liebe, Ehe und Sexualität im vorreformatorischen Meistersang. Texte und Untersuchungen. Göppingen 1995 (GAG 624); Michael BALDZUHN: Vom Sangspruch zum Meisterlied. Untersuchungen zu einem literarischen Traditionszusammenhang auf der Grundlage der Kolmarer Liederhandschrift. Tübingen 2002 (MTU 120); EGIDI (s.o.); DIETLIND GADE: Wissen - Glaube - Dichtung. Kosmologie und Astronomie in der meisterlichen Lieddichtung des vierzehnten und fünfzehnten Jahrhunderts. Tübingen 2005 (MTU 130).

${ }^{3}$ Den Ansatz eines eigenen Abschnitts der Gattungsgeschichte zwischen Sangspruchdichtung einerseits und Meistergesang andererseits begründet ausführlich FRIEDER SCHANZE: Meisterliche Liedkunst zwischen Heinrich von Mügeln und Hans Sachs. München 1983-84 (MTU 82/83), Bd. 1, S. 7-11. Diesen Ansatz vollzieht auch die grundlegende Einleitung im RSM, Bd. 1, S. 2f., mit. Vgl. auch HELMUT TERVOOREN: Sangspruchdichtung. Stuttgart/Weimar 1995 (Sammlung Metzler 293), S. 124-126. Grundsätzliche Überlegungen zu den Anforderungen, die die weitere Erschließung dieses Gattungsausschnitts stellt, sowie zu ihren Möglichkeiten und Grenzen bei KARL STACKMAnN: Das anonyme meisterliche Lied. Versuch über ein Problem der spätmittelalterlichen deutschen Literatur. ZfdA 128 (1999) 377-393 (wieder abgedruckt in ders. [Anm. 2], S. 182-200 [danach hier zitiert]). 
bereits in Aufzeichnungen im Vorauer Codex 401 zu Anfang des 14. Jahrhunderts ( ${ }^{1} \mathrm{Regb} / 1 / 101 \mathrm{f}$.) und in Manesse-C ( $\left.{ }^{1} \mathrm{Regb} / 1 / 1-5\right){ }^{4}$ Sie erstreckt sich bis weit ins 16 . Jahrhundert hinein, in dem die Meistersinger Regenbogen als einen der zwölf alten Meister verehren werden. ${ }^{5}$ Und sie umfaßt über eineinhalb Tausend Strophen. ${ }^{6}$

$\mathrm{Da} \beta$ aus dieser Textmasse einstweilen nur gut zwei Handvoll Strophen mit einiger Gewißheit dem Tonerfinder Regenbogen zugewiesen werden können, mag denjenigen stören, dem an einer Profilierung des echten Regenbogen gelegen ist. ${ }^{7}$ Auf eine solche zielt der vorliegende Beitrag indes nicht, sondern auf die durchschnittliche Ausgestaltung des Sprechens von Minne zwischen Regenbogen und dem jungen Hans Sachs. Denn es ist ja beim gegenwärtigen Wissensstand schon viel gewonnen, wenn es überhaupt gelingt, einzelne Texte überhaupt mit größerer Sicherheit eher ins 14. Jahrhundert setzen zu können, in jene überaus produktive, aber noch kaum konturierte nachfrauenlobsche Spätphase des Sangspruchs, andere Ausformungen eher an das im 15. Jahrhundert an Prominenz gewinnende Liederbuchlied anschließen und weitere schließlich mit größerer Wahrscheinlichkeit im unmittelbaren Vorfeld des sich institutionalisierenden Meistergesangs verorten zu können. Vorgearbeitet werden soll also vom Regenbogen-Korpus her einer weitergehenden Einsicht in die Verschiebungen, denen das Verhältnis von Minnesang bzw. späterem Liederbuchlied und Sangspruch bzw. meisterlichem Lied im Rahmen des insgesamt in Bewegung geratenden Systems der lyrischen Gattungen im 14. und 15. Jahrhundert unterliegt. $^{8}$ Dafür gerade am Regenbogen-Korpus anzusetzen, kann

${ }^{4}$ Vgl. zur Vorauer Handschrift 401 Frauenlob (Heinrich von Meissen). Leichs, Sangsprüche, Lieder. Auf Grund der Vorarbeiten von Helmuth ThOMAS hg. von KARL STACKMANN und KARL BERTAU. Göttingen 1981 (Abhandlungen der Ak. der Wiss. in Göttingen. Phil.-hist. Kl., 3. Folge, Nr. 119/120), Bd. 1, S. 116-119, SCHRÖDER [Anm. 2], S. 204f., und RSM, Bd. 1, S. 262.

${ }^{5}$ Dazu im Überblick SCHANZE [Anm. 2], Sp. $1083 \mathrm{f}$.

${ }^{6}$ Diese Zahlenangabe zum vorreformatorischen Bestand nach KoRNRUMPF [Anm. 2], S. 332 .

${ }^{7} \mathrm{Zu}$ den Echtheitsfragen zuletzt JOHANNES RETTELBACH: Sangspruchdichtung zwischen Frauenlob und Heinrich von Mügeln - eine Skizze. In: Studien zu Frauenlob und Heinrich von Mügeln. Fs. für Karl Stackmann zum 80. Geb. Hg. von JENS HAUSTEIN und RALF-HENNING STEINMETZ. Freiburg/Schweiz 2002 (Scrinium Friburgense 15), S. 145-174, hier S. 152f.

${ }^{8}$ Dazu eine grundlegende Skizze bei HORST BRUNNER: Das deutsche Liebeslied um 1400. In: Gesammelte Vorträge der 600-Jahrfeier Oswalds von Wolkenstein. Seis am Schlern 1977; Dem Edeln unserm sunderlieben getrewn Hern Oswaltten von Wolkchenstain. Hg. von HANS-DIETER MÜCK und ULRICH MÜLLER. Göppingen 1978 (GAG 206), S. 105-146. Vgl. weiterhin HORST BRUNNER: Tradition und Innovation 
einstweilen einzig aus forschungsstrategischen, aus pragmatischen Gründen eben mit der tendenziell repräsentativen Breite des Ausschnitts gerechtfertigt werden. Über zuverlässigere Anhaltspunkte, die eine begründetere Auswahl rechtfertigten, verfügen wir im Moment nicht. Daß indes das Sprechen über Minne in der späten Sangspruchdichtung und im vorreformatorischen Meistergesang durchgreifende Änderungen erfährt, läßt sich mit Gewißheit erwarten. Bereits der soziologische Wandel, dem Sangspruch und meisterliches Lied auf ihrem Weg ins Gemerk der Meistersinger unterliegen, distanziert sie zunehmend vom traditionellen höfischen Liebesdiskurs. ${ }^{9}$ Während höfische Liebe als integrales Element des adeligen Selbstverständnisses fungiert, werden die Meistersinger des 16. Jahrhunderts den Vortrag von sogenannten Buhlliedern in ihren Gemerken teils ausdrücklich untersagen. ${ }^{10}$ Hans Sachs, Meistersänger par excellence, wird Liebeslieder nur am Rande der Meistertradition verfassen und sie in seinem >Generalregister getrennt von seinen Meisterliedern verzeichnen. ${ }^{11}$ Wenn vor die-

im Bereich der Liedtypen um 1400. Beschreibung und Versuch der Erklärung. In: Textsorten und literarische Gattungen. Dokumentation des Germanistentages in Hamburg vom 1. bis 4. April 1979. Hg. vom Vorstand der Vereinigung der deutschen Hochschulgermanisten. Berlin 1983, S. 392-413; HORST BRUNNER: Das deutsche Lied im 16. Jahrhundert. In: Fragen der Liedinterpretation. Hg. von HEDDA RAGOTZKY u.a. Stuttgart 2001, S. 118-134; BURGHART WACHINGER: Liebeslieder vom späten 12. bis zum frühen 16. Jahrhundert. In: Mittelalter und frühe Neuzeit. Übergänge, Umbrüche und Neuansätze. Hg. von WALTER HAUG. Tübingen 1999 (Fortuna Vitrea 16), S. 1-29. Vgl. jetzt auch die Beiträge insbesondere von MANFRED KERN, GERT HÜBNER, SABINE OBERMAIER, HARALD HAFERLAND und HORST BRUNNER in: Deutsche Liebeslyrik im 15. und 16. Jahrhundert. 18. Mediävistisches Kolloquium des Zentrums für Mittelalterstudien der Otto-Friedrich-Universität Bamberg am 28. und 29. November 2003. Hg. von GERT HÜBNER. Amsterdam/New York 2005 (Chloe. Beihefte zum Daphnis 37).

${ }^{9} \mathrm{Zu}$ verweisen ist hier auf den grundlegenden Entwurf einer »historischen Typologie der Gattung zwischen dem 14. und dem 16. Jahrhundert" von SCHANZE [Anm. 3], Bd. 1, S. 369-392.

${ }^{10}$ WILIBALD NAGEL: Studien zur Geschichte der Meistersänger. Langensalza 1909 (Musikalisches Magazin 27), S. 70; OTTO PlATE: Die Kunstausdrücke der Meistersinger. Straßburger Studien 3 (1888) 147-224 [in gekürzter Form wieder abgedruckt in: Der deutsche Meistergesang. Hg. von BERT NAGEL. Darmstadt 1967 (WdF 148), S. 206-263], hier S. 189.

${ }^{11}$ JUlia-MARIA HeinzmanN: Die Buhllieder des Hans Sachs. Form, Gehalt, Funktion und sozialhistorischer Ort. Wiesbaden 2001 (Gratia 38); JOHANNES RETTELBACH: Die frühen Liebeslieder von Hans Sachs. In: Deutsche Liebeslyrik im 15. und 16. Jahrhundert [Anm. 8], S. 201-220; Das handschriftliche Generalregister des Hans Sachs. Reprintausgabe nach dem Autograph von 1560 des Stadtarchivs Zwickau von Hans Sachs mit einer Einführung von REINHARD HAHN. Köln/Wien 1986 (Literatur und Leben N. F. 27), Bl. 73' $-74^{\text {r }}$. Vgl. zum Aufbau des >Generalregisters S. 14 in der Einführung HaHNs sowie zur Stellung der Buhllieder HEINZMANN S. 88-90. 
sem Hintergrund Hans Folz in Nürnberg ein regelrechtes Liebeslied in einem Spruchton verfaßte: dichtete er dann eher im Kontakt zum zeitgenössischen Nürnberger Gesellschaftslied - oder nicht vielleicht doch in der Manier und in Kenntnis letzter Ausläufer einer späten Praxis der höfischen Sangspruchdichter des 14. Jahrhunderts? ${ }^{12}$

Drei kurze Vorbemerkung zur Methode. Was den Aufbau des Textkorpus anbelangt, wurde pragmatisch und bewußt offen verfahren: Der thematische Schwerpunkt der Texte mußte nur irgendwie auf Minne, Liebe, Frauen (mit Ausnahme der Gottesmutter Maria), Sexualität liegen. Die Linien, die dem entsprechenden Textkorpus, das sich auf ungefähr 180 Strophen in fast 40 Überlieferungseinheiten (>Liedern`) beläuft, ${ }^{13}$ eingezogen werden sollen, ergeben sich aus der Anwendung eines Bündels sehr verschiedenartiger Kriterien: Es mischen sich Befunde zur Überlieferungsgeschichte, Beobachtungen zu den Typen von Textvarianz im Bereich der Strophenordnungen und zur Ausgestaltung der Sprecherposition mit mehr oder minder zufälligen Beobachtungen zu Textdetails, Bezüge etwa zum wîp-vrouwe-Streit, zu inhaltlich-thematischen Schwerpunktsetzungen und gestalterisch-stilistischen Charakteristika. Drittens schließlich: Als orientierende Leitlinie dient - in Anlehnung an die Untersuchung von EGIDI - die Unterscheidung zwischen Mahnsprüchen, Strophen, die den Minneprozeß selbst zum Gegenstand haben, und Preisliedern, für die, über EGIDI hinaus, zwischen objektivem und subjektivem Frauenpreis unterschieden wird.

${ }^{12}$ Die Meisterlieder des Hans Folz aus der Münchener Originalhandschrift und der Weimarer Handschrift Q. 566 mit Ergänzungen aus anderen Quellen hg. von AUGUST L. MAYER. Berlin 1908. Unveränderter Nachdruck Hildesheim 2001 (DTM 12), Nr. 69 ('Folz/69: "INHALT: Liebeslied mit Werbung, Klage und Liebesbeteuerungen «); JOHANNES JANOTA: Liebe und Ehe bei Hans Folz. Von der Minnerede zum Lob der Ehe. In: Liebe in der deutschen Literatur des Mittelalters. St. Andrews-Colloquium 1985. Hg. von JEFFREY ASHCROFT u.a. Tübingen 1987, S. 174-191, hier S. 177, weist auf dieses Lied, das in einem namenlosen und nur hier einmal verwendeten Ton verfaßt ist, lediglich kurz hin, ohne es weitergehend zu besprechen. Zur weltlichen Liebe als Thema Folzscher Lieder im Überblick SCHANZE [Anm. 3], Bd. 1, S. 334f., zum speziell für Lied Nr. 69 verwendeten Ton kurz RETTELBACH [Anm. 2], S. 304.

Die Monografie von ScHULZ [Anm. 2] erbringt für die Frage nach den Transformationen des Sprechens von weltlicher Liebe im meisterlichen Lied bis zur Institutionalisierung des Meistergesangs im übrigen weniger, als die Titelgebung "Liebe, Ehe und Sexualität im vorreformatorischen Meistersang « erhoffen läßt: Sie hat ihren Wert vor allem darin, daß einige bisher ungedruckte Lieder des fraglichen Themenbereichs zugänglich gemacht werden. Das Textkorpus ist aber ohne weitergehend durchsichtige Kriterien zusammenstellt. Auch werden die einzelnen Lieder mit allzu oberflächlichunscharfen Kategorien analysiert.

${ }^{13}$ Für den Einzelnachweis siehe die Tabelle in Anhang 1. Für den Ansatz der jeweiligen Liedeinheit halte ich mich im folgenden allein aus praktischen Gründen ans RSM. 
Zahlreiche Lieder erfordern eine detailliertere Analyse, als sie im Rahmen dieses Beitrags geleistet werden kann. Auch sind die Zuordnungen einzelner Texte zu ihren Gruppen nicht immer eindeutig und wären breiter zu diskutieren. Verkürzungen sind jedoch der Preis für das Wagnis eines generalisierenden Vorgriffs. Um dessen wesentlichen Ertrag daher schon einleitend zu benennen: Insbesondere im Typ des subjektiven Liebesliedes zeichnen sich engere Verbindungen zum nicht-meisterlichen Liederbuchlied ab; an ihm werden überdies ausgeprägte Literarisierungstendenzen des frühen meisterlichen Liedes ablesbar, die sich auch übergreifend, d.h. auch an den anderen Textgruppen, erkennen lassen und die der späten Sangspruchdichtung ein beachtenswertes eigenes Profil verleihen. Darauf ist, nach dem kursorischen Durchgang durch das Textmaterial, in einer Zusammenfassung der Befunde am Schluß noch einmal zurückzukommen.

\section{Mahnsprüche}

Dezidiert ermahnende Minnesprüche, in denen die Frau auf ein als gültige Norm propagiertes Verhalten verpflichtet werden soll, sind in der älteren Sangspruchdichtung in Vielzahl belegt. ${ }^{14}$ An diese Praxis knüpft noch Regenbogen selbst an, der als Verfasser eines entsprechenden Spruchs aus C in der Briefweise gilt $\left({ }^{1} \mathrm{Regb} / 1 / 5\right.$ : Vünf hande tugend sol ein reine vrouwe pflegen, wil sie behalten völleklichen segen)..$^{15}$ Der Tonerfinder und Textdichter läßt hier ein Ich in der altbekannten Rolle des Sangspruchdichters auftreten, der im wesentlichen gemeinhin Gewußtes zur Sprache bringt, kollektiv geteiltes Wissen in

\footnotetext{
${ }^{14}$ Vgl. EGIDI [Anm. 2], S. 86-136 und die Belegübersicht S. 404-407. Von den nachstehend genannten Sprüchen und Liedern ${ }^{1} \operatorname{Regb} / 1 / 5,{ }^{1} \operatorname{Regb} / 1 / 511,{ }^{1} \operatorname{Regb} / 1 / 521$ und ${ }^{1} \mathrm{Regb} / 4 / 656$ sind die ersten drei Nummern an entsprechender Stelle (S. 405f.: »Ermahnende Minnesprüche «) in die Belegübersicht von EGIDI aufgenommen. $\mathrm{Zu}$ ${ }^{\prime} \mathrm{Regb} / 1 / 511$ wird »mit Frauenpreis « und »Ehespruchstrophen « bemerkt, so daß es auch S. 410 unter »Frauenpreis« und S. 414 unter »Ehestrophen« (dort: »mit Berührung zum höfischen Liebesdiskurs, d.h. mit höfischem Vokabular«) noch einmal erscheint. Das vierte Lied ist dagegen nirgends berücksichtigt. Im Darstellungsteil findet keiner der Texte Berïcksichtigung.

$\mathrm{Zu}$ den dem entsprechenden Abschnitt des Belegverzeichnisses von EGIDI zusätzlich zugeordneten Liedern ${ }^{1} \operatorname{Regb} / 1 / 541$, ' $\operatorname{Regb} / 1 / 545$ und ${ }^{1} \operatorname{Regb} / 3 / 15$ s.u. Abschnitt 3 ("Lieder von der ambivalenten Macht der Frau«), zu den zusätzlich zugeordneten Liedern ${ }^{1}$ Regb/4/563 und ${ }^{~}$ Regb/4/617 s.u. Abschnitt 4 ("Objektiver Frauenpreis «).

${ }^{15}$ Text: Minnesinger. Deutsche Liederdichter des zwölften, dreizehnten und vierzehnten Jahrhunderts, aus allen bekannten Handschriften und frühen Drucken gesammelt und berichtigt [...] von FRIEDRICH HEINRICH vON DER HAGEN. Leipzig 1838, Bd. 2, S. 309 .
} 
Erinnerung ruft und den Frauen rät, auch hier und jetzt wieder und zukünftig ihr Handeln entsprechend auszurichten: mit triuwen das rat $i c h$ heißt es entsprechend an einer Stelle. ${ }^{16}$ In vorliegenden Fall wird an den Bedingungszusammenhang erinnert, in dem himmlisches und irdisches Heil und die fünf Tugenden êre, zuht, bescheidenheit, kiusche und milte stehen.

Der Mahnspruch aus $\mathrm{C}$ hat in der Eingangsstrophe eines einzig aus der $>$ Kolmarer Liederhandschrift $<\mathrm{k}$ bekannten Dreierbars ein unmittelbares Echo gefunden: Siben tugende sol ein ieclich frouwe haben: hât si der niht, ir wîplich êre diu muoz snaben $\left({ }^{1} \mathrm{Regb} / 1 / 511\right) .{ }^{17}$ Die aus sich heraus verständliche Strophe läßt den Bezug zum Vorbild bereits an der speziellen Themenwahl, am Gestus der steigernden Überbietung - aus fünf Tugenden werden sieben - und bis in den beiden Sprüchen gemeinsamen, abschließenden Ausblick auf das himmlische Heil hinein erkennen. Da in k noch zwei weitere Strophen beigegeben sind, deren letzte erneut mit eben einem solchen Ausblick schließt, ist zudem eine mehrschrittige Entstehung des Bars aus Einzelstrophen zu erwägen: Dies ist, neben den besonderen textlichen Bezügen, ein weiteres Argument für eine Entstehung des Liedes und seiner Teile noch im zweiten oder dritten Viertel des 14. Jahrhunderts. ${ }^{18}$

Neben der Anlehnung an den altbezeugten Modellspruch ist es auch die Art und Weise selbst, in der hier von Frauen gesprochen wird, die das gesamte spätüberlieferte k-Lied als bedeutend älter erweisen. Denn mehr oder minder explizit an die Frau gerichtete Lehre und Mahnung,

${ }^{16}$ Vgl. KaRL StackmanN: Der Spruchdichter Heinrich von Mügeln. Vorstudien zur Erkenntnis seiner Individualität. Heidelberg 1958 (Probleme der Dichtung 3), S. 100f.; Klaus Grubmüller: Die Regel als Kommentar. Zu einem Strukturmuster in der frühen Spruchdichtung. Wolfram-Studien 5 (1979) 22-40, hier S. 38-40; TERVOOREN [Anm. 3], S. 48f.; KARIN BREM: >Herger/Spervogel. Die ältere Sangspruchdichtung im Spannungsfeld von Konsenszwang und Profilierung, Konformität und Autorität. ZfdPh 119 (2000), Sonderheft »Neue Forschungen zur mittelhochdeutschen Sangspruchdichtung $\ll$, S. 10-37.

${ }^{17}$ Text: Meisterlieder der Kolmarer Handschrift. Hg. von KARL BARTSCH. Stuttgart 1862 (StLV 68). Nachdruck Hildesheim u.a. 1998, Nr. 60.

${ }^{18}$ Eine Abhängigkeit von ${ }^{1}$ Regb/1/5 hat bereits SCHRÖDER [Anm. 2], S. 196 Anm. 69 konstatiert: »Frauenlehre [...], die die Regenbogen-Str. C 5 [...] ausschreibt«. Vgl. zur Strophengebrauchspraxis im Hintergrund des Dreierbars ausführlich BALDZUHN [Anm. 2], zusammenfassend etwa S. 499 (»Mit vortragsseitig wechselnden Strophenordnungen ist noch in den Dichtungen des Harder zu rechnen, d.h. bis in den Anfang des letzten Viertels des 14. Jahrhunderts hinein. Allzu weit über das dritte Jahrhundertviertel hinaus wurden unfeste Strophen wohl nicht mehr verwendet.«). BARTSCH ([Anm. 17], S. 176) wollte das ganze Bar noch in der ersten Hälfte des 14. Jahrhunderts entstanden wissen, gibt jedoch keine näheren Gründe an. 
die deutlich einem den allgemein bekannten Komment aufrufenden Sprecher in den Mund gelegt ist, prägt ganze Lieder in RegenbogenTönen prinzipiell eher selten. Außer dem Einzelspruch aus $\mathrm{C}$ und dem vielleicht sekundär zusammengesetzten Bar aus $\mathrm{k}$ tritt solcherart ausgeformte Frauenmahnung nur noch in einem weiteren dreistrophigen Lied - es ist wiederum einzig aus der >Kolmarer Liederhandschrift< bekannt - in Erscheinung. In ihm klagt das Ich - stellvertretend für >alle anderen < - speziell über jene Frauen, die sich auf Liebeshändel mit Geistlichen einlassen ( ${ }^{1} \mathrm{Regb} / 1 / 521$ : Sô wê der frowen, daz sie $\hat{u} f$ erde ie wart geborn, die einen pfaffen ir ze liebe hât erkorn). ${ }^{19}$ Wiederum legt es in wîsem rât $t^{20}$ die weiterreichenden Konsequenzen solchen Verhaltens dar. Einzelne Textdetails legen wiederum eine Kenntnis zumindest der siben tugende-Trias, wenn nicht sogar des alten C-Spruchs nahe. ${ }^{21}$ Das könnte ein Hinweis auf eine wohl eher kleinräumige Produktionstradition im Bereich des dezidiert mahnenden Lehrspruchs und seiner wenigen Ausläufer im mehrstrophigen Lied sein. $^{22}$

Gestützt zu werden scheint mir dieser Ansatz einer kleinen Gruppe alter, zusammengehöriger Texte auch dadurch, daß ein weiteres Lied $\left({ }^{1} \mathrm{Regb} / 4 / 656:\right.$ Jr reinen frawen, nemet ware vnd merckt einen scharpffen list, den ich kunt dun $)^{23}$ nun gerade nicht in der Briefweise, sondern

${ }^{19}$ Text: BARTSCH [Anm. 17], Nr. 65.

${ }^{20} \mathrm{Vgl}$. den prononcierten Schlußvers der ganzen Strophentrias (sô tuont ir reht vnd volgent wiser rate) sowie zuvor bereits die dezidierte Exposition des SpruchdichterIch als Verkünder autoritativ verbürgter Warheit im letzten Aufgangsvers der Eingangsstrophe (ich spriche daz und ist auch wâr, man vindetz an den buochen).

${ }^{21}$ Alle drei Sprüche und Lieder variieren den alten Kaisertopos ('Regb/1/5, v. 11; ${ }^{1} \operatorname{Regb} / 1 / 511$, Str. 3, v. 2; ${ }^{1}$ Regb/1/521, Str. 3, v. 1). Alle drei heben explizit auch auf Sicherung geistlichen Heils ab ( ${ }^{1} \operatorname{Regb} / 1 / 5$, v. 13 [Schlußvers]; ${ }^{1} \operatorname{Regb} / 1 / 511$, Str. 1, v. 13 [Schlußvers] und Str. 3, v. 13 [Schlußvers]; ${ }^{1}$ Regb/1/521, Str. 1, v. 11, Str. 2, v. 12, und Str. 3, v. 3). Alle drei arbeiten mit Bildvorstellungen von der Straße, vom »Pfad der Ehre" oder vom zum Palast der Frau Ehre führenden "Pfad der Lehre « ('Regb/1/5, v. 8; ${ }^{1} \operatorname{Regb} / 1 / 511$, Str. 2, v. 2f.; 'Regb/1/521, Str. 2, v. 7). Im Einzelfall ist das angesichts der weiteren Verbreitung der Motive - vgl. für den Kaisertopos die Hinweise bei ScHULz [Anm. 2], S. 254f. - nicht aussagekräftig, aber wohl in der Summe.

${ }^{22}$ Ich verweise überdies wiederum nur deshalb auf BARTSCHs Urteil ([Anm. 17], S. 176), der das Lied ' Regb/1/521 noch dem Tonerfinder selbst zuschreiben wollte, um zu verdeutlichen, daß zumindest keine allzu offenkundigen Gründe gegen ältere Entstehung des Liedes sprechen - und nicht, weil ich das Lied mit BARTSCH Regenbogen zuweisen wollte. Die Warnung vor der »Pfaffenminne « ist im übrigen ein im anonymen meisterlichen Lied häufiger wiederkehrendes Thema, das - zuvörderst im Hinblick auf Geistliche als zeitgenössische Träger der Liedkunst im 14. Jahrhundert einmal nähere Untersuchung verdiente.

${ }^{23} \mathrm{Vgl}$. den Textabdruck des bisher unedierten Liedes unten im Anhang 2. 
im Langen Ton verfaßt ist - man kannte also diese kleine Tongebrauchstradition nicht mehr - und auch seiner Überlieferung nach herausfällt, da es erst die vom jungen Hans Sachs geschriebene Meisterliederhandschrift q bezeugt. Eine Sonderstellung nimmt es kaum zufällig auch im Strophenumfang ein - es handelt sich jetzt um ein Fünferbar - und hinsichtlich der Ausgestaltung der Heilsdimension. Das Heil nämlich, das sich die Frau durch richtiges Verhalten erwerben kann, erscheint weitgehend auf den Aspekt des Physischen verkürzt. Die Unterweisung zielt alleine noch auf das richtige Verhalten der Frau während der Schwangerschaft und bei der Geburt, um Schaden von sich und dem Kind abzuwenden. Dabei geriert sich das auftretende Ich freilich selbst nun derart dezidiert als Propagator von Buchwissen, durch Verweise auf Albertus Magnus etwa (Str. 4, v. 1) und die ler naturlicher meister und die geschriftt (Str. 5, v. 13 und 15), daß der Spruchton hier schon fast wie eine Hohlform verwendet erscheint, in die sich beliebig Wissen hineingießen lie $B .{ }^{24}$ Damit tritt die Instruktion der Frauen nach Maßgabe des aufgerufenen gesellschaftlichen Komments - den freilich nicht die Gesellschaft selbst, sondern der Spruchdichter an ihrer statt ausformuliert, der besondere Akzente setzen sowie sich damit zugleich als besonders leistungsfähiger Vermittler profilieren kann - als Anliegen des Textes stärker hinter die Exposition des Sängers zurück als jemand, der eine künstlerische Form beherrscht und der über Fachwissen aus der gelehrt-lateinischen Sphäre verfügt. An die Stelle des gesellschaftlichen Komments tritt das Buch - oder genauer: der unausgesprochene Komment erscheint nunmehr durch die Schriftlichkeit des Buches gebrochen. Auch von daher gesehen, gehört das Fünferbar aus der Hans-Sachs-Handschrift q gewiß nicht mehr in diese um den alten C-Spruch herum aufzubauende Gruppe älterer Mahnsprüche. ${ }^{25} \mathrm{Da}$ diese ältere Gruppe als solche aber insgesamt sehr überschaubar bleibt, zeigt - zumal dann, wenn man die mehrseitige Belegliste entsprechender Strophen im Anhang der Arbeit von EGIDI vor Augen hat ${ }^{26}$ - einen deutlichen Attraktivitätsverlust einer Ausge-

\footnotetext{
${ }^{24}$ So nutzt im 15. Jahrhundert auch Michel Beheim die Gattung. Vgl. BuRGHART WACHINGER: Michel Beheim. Prosabuchquellen - Liedvortrag - Buchüberlieferung. In: Poesie und Gebrauchsliteratur im deutschen Mittelalter. Würzburger Colloquium 1978. Hg. von VOLKER HONEMANN u.a. Tübingen 1979, S. 37-75.

${ }^{25}$ Es steht hingegen ganz offensichtlich schon qua Themenwahl sowie durch die erwähnten Berufungen auf die schrifft gelehrte Autoritäten mit einer anderen Gruppe von Liedern im Langen Ton, der überhaupt bevorzugt für gelehrte Inhalte hinzugezogen wurde, in einer engen Verbindung. Vgl. zu dieser Gruppe kosmologischer, hydreologischer und gynäkologischer Bare GADE 2001 [Anm. 4] ('Regb/4/656 dort noch nicht berücksichtigt).

${ }^{26}$ EGIDI [Anm. 2], S. 404-407.
} 
staltung des Sängerauftritts an, in der dieser als Sprachrohr des allgemeinen Gewußten in verallgemeinender Weise über die Frauen insgesamt und in belehrender Absicht spricht. Daß Heinrich von Mügeln von seinen sieben von STACKMANN untersuchten Minnespruchgruppen lediglich zwei als allgemeine Minnelehre ausgestaltet, weist genau in dieselbe Richtung. ${ }^{27}$

\section{Beschreibung des Minneprozesses}

Im Unterschied zum Mahn- und Lehrspruch ist die Beschreibung des Minneprozesses als solchen in der älteren Sangspruchdichtung ohnehin weniger verbreitet gewesen. ${ }^{28}$ Unter den anonymen Nachsängern, das ist zumindest der aus den Regenbogen-Tönen zu ziehende Schluß, reduziert sich der Anteil entsprechender Texte noch weiter. Ein Interesse, über die Minne selbst in ihren Erscheinungsformen und besonderen Wirkungen zu sprechen, scheint so gut wie gar nicht mehr bestanden zu haben. Nur in einem einzigen dreistrophigen Lied in der Briefweise ( ${ }^{1} \mathrm{Regb} / 1 / 561:$ Wa herze liep an herze liebes arme lit, da wirdet vröude hohe), ${ }^{29}$ das von der Gewalt der Minne handelt, schlägt es sich in den Regenbogen-Tönen nieder. Dieses Lied aber wird, kaum zufällig, statt in einer die Gattung breiter dokumentierenden Handschrift lediglich von einem Überlieferungszeugen bewahrt, der ganz am Rande der Gattungstradition steht: vom 1431 in Livland von einem niederrheinischen Schreiber vielfach nach hochdeutschen Vorlagen des 14. Jahrhunderts geschriebenen Berliner Mgo 186, das in Sangspruchtönen überhaupt nur dieses eine Lied bewahrt. ${ }^{30}$ In solchem Kontext muß man das entsprechende Dreierbar in der Briefweise wie ein Relikt betrachten, das als Gelegenheitseintrag, der zwischen einer Minnerede und einem Märenfragment zu stehen kam - mehr zufällig aufbewahrt wurde, gewiß aber keiner lebendigen Produktionspraxis im Umfeld der (späten) Aufzeichnung sich verdankt. ${ }^{31}$

\footnotetext{
${ }^{27}$ Stackmann [Anm. 2].

${ }^{28}$ Vgl. EGIDI [Anm. 2], S. 137-183, sowie die Belegübersicht S. 407f.

${ }^{29}$ Text: vON DER HAGEN [Anm. 15], Bd. 3, S. 452f. (bei EGIDI [Anm. 2] S. 408 gelistet).

${ }^{30}$ Vgl. zur Handschrift RSM, Bd. 1, S.91, sowie über die dort angegebene Literatur hinaus SCHRÖDER [Anm. 2], S. 196 Anm. 68.

${ }^{31}$ Dazu paßt prinzipiell wiederum, daß sich "gewisse Stilzüge sogar mit Regenbogen selbst in Verbindung « bringen lassen (SCHRÖDER [Anm. 2], S. 196 Anm. 68). Das Lied hat, von SCHRÖDERs Anmerkung abgesehen, noch keinerlei weitere Berücksichtigung in der Forschung erfahren. Auch EGIDIs Darstellungsteil übergeht es. Eine bereits produktionsseitige dreistrophige Anlage wird durch die homogene Themenstellung sowie durch die nahezu unveränderte Wiederaufnahme des Eingangsverses
} 
Allenfalls eine Einleitungsstrophe zu einem noch mit alten Einzelsprüchen hantierenden Dreierbar aus der Kolmarer Liederhandschrift im Langen Ton Regenbogens ließe sich noch hierher stellen und der Kleinstgruppe zuordnen ( ${ }^{1} \mathrm{Regb} / 4 / 508 \mathrm{a}$ : Got schuof ein wunder in der mâze, dô er maht Adâm und Evâ zer selben stunt).$^{32}$ In der Eingangsstrophe wird von der Minne als solcher und ihren Wirkungen bezeichnenderweise in der Form des Rätsels gesprochen. Die Mittelstrophe begegnet in völlig ausgetauschter Strophennachbarschaft noch einmal in der >Weimarer Liederhandschrift $<\mathrm{f}^{33}$ Es bedurfte mithin bereits schon zu Zeiten, in denen man noch mit alten Einzelstrophen hantierte, der lebendigeren Darstellungsform des Rätsels, um das vergleichsweise abstraktere Sprechen von der Minne selbst noch mit Erfolg vor ein Publikum zu bringen.

\section{Profilierung des höfischen Sängers als Kämpfer und Erzähler: Lieder von der ambivalenten Macht der Frau}

Die zwei auf die einleitende Rätselstrophe folgenden Strophen, die die alte Mittelstrophe in ${ }^{1}$ Regb/4/508a in den Rahmen der moderneren Barform bringen, binden das ohnehin schon durch die Rätselform aufgewertete Minnethema überdies auf eine ganz charakteristische Weise an zeitgenössische Publikumserwartungen an. Beginnend mit dem alten Einzelspruch der Mittelstrophe, folgen auf das Eingangsrätsel zwei Reihen von Exempla für die Macht der Frauen. Die Minnesklaven Adam, Samson, David, Absalon, Alexander, Vergil, Alexander, Holofernes

(Wa herze liep an herze liebes arme lit, da wirdet vröude hohe) im Schlußvers der letzten Strophe (wa herzelieb an herzeliebes arme ligt, da ist alliu vröude entsprozzen) sehr nahe gelegt. Mit weiter unten noch vorzustellenden Texten verbindet es im übrigen besonders auffällig die Vorstellung von der Minne als Antrieb zu ritterlichem Turnierkampf (Str. 1, v. 9-11: Diu minne tuot schilt unde sper zebrechen, mit hurten unt tschostieren ros und mannes lip versuochet wirt durch die suezen minne unt al diu werden wip) sowie die von der potentiell herausfordernden Frage am Schlußvers der Eingangsstrophe eröffnete Möglichkeit, das Bild vom Ritterkampf in die poetologische Sphäre des Sängerwettstreits zu übertragen (Str. 1, v. 12f.: der werlde wunne und aller vröuden leit vertrip an werder suezer minne lit: wer mak daz sprechen?).

${ }^{32}$ Text: BARTSCH [Anm. 17], Nr. 81. Bei TOMAS TOMASEK: Das deutsche Rätsel im Mittelalter. Tübingen 1994 (Hermaea. N.F. 69), ist die Eingangsstrophe nicht berücksichtigt. EGIDI [Anm. 2] listet sie im Beleganhang an entsprechender Stelle (S. 408) und kann auf inhaltliche Parallelen in anderen Liedern verweisen (vgl. S. 237 Anm. 817). BARTSCH [Anm. 17], S. 607, dachte für den Verfasser des ganzen Liedes an einen »nicht viel jüngern [...] dichter« als Regenbogen.

${ }^{33} \mathrm{Vgl}$. für die Diskussion von Überlieferung und Zusammengehörigkeit der drei Strophen SCHANZE [Anm. 3], Bd. 1, S. 86, und BALDZUHN [Anm. 2], S. 297. Siehe auch unten in Abschnitt 4 zu ${ }^{1}$ Regb/4/617a. 
und Aristoteles belegen diese Macht in ihren negativen Auswirkungen, gegen die weder mit Kraft noch mit wîsheit anzukommen sei. In der dritten Strophe hingegen wird die Macht der Frauen dann positiver aufgefaßt: als Antrieb zu mannhafter Tat, die mit den trojanischen Helden Hektor und Achilles ebenso wie mit Figuren aus der mittelhochdeutschen Romanliteratur, mit Artus selbst, mit Lûnete und Parzival belegt wird: sus hulfen wîp in arebeit den besten, die beschein der êren sal (Str. 3, v. 20f.). Wie die Verwendung des alten Einzelspruchs und der Anschluß an den arthurischen Versroman, so verweist auch diese ambivalente Perspektivierung der Macht der Frauen noch in die späte Sangspruchdichtung zurück. Von der Macht der Frauen handelt nämlich eine ganze Reihe weiterer Lieder, die überdies eine aufschlußreiche autoreferentiell-poetologische Einfärbung dieses Themas verbindet. Im Einzelfall ist diese Einfärbung mehr oder minder deutlich zu greifen. Gleichwohl zeigt sie durchgängig eine gewisse Aufwertung der vorgetragenen Strophen und Lieder an, insofern diese ihre Funktion, als Medium der Selbstverständigung der höfischen Gesellschaft zu dienen, nicht einfach nurmehr lediglich erfüllen, sondern regelmäßig nun auch herausstellen. Im Zuge solcher Herausstellung dürfte dann auch auf der anderen Seite, auf der Seite des Publikums, diese Selbstverständigung wohl weniger noch über eine unmittelbare Identifikation mit den propagierten Werten selbst oder über ihre Diskussion gelaufen sein als vielmehr über eine Ästimierung und Diskussion des Textvortrags als solchen.

Im Ansatz arbeitet bereits die Rätselform der Eingangsstrophe von ${ }^{1} \mathrm{Regb} / 4 / 508 \mathrm{a}$ diesem Hervortreten des Spruchdichters entgegen: insofern sie den Vortragenden vor den Zuhörern nämlich als Rätselsteller und damit in besonderer Weise exponiert. Das ließe sich, isoliert betrachtet, noch kaum grundsätzlicher belasten. Diesen Einwand zieht zunächst wohl auch das allein von $\mathrm{k}$ überlieferte Fünferbar ${ }^{1} \mathrm{Regb} / 1 / 541$ auf sich, das sich im Eingangsvers an die werden ritter wendet (Str. 1, v. 1f.: Nu hoerent mich ir werden ritter und ir kneht, ich wil iu geben lêre $).^{34}$ Ihnen werden die frouwen als lebenspendender Ansporn zu höfischer Lebensart und Bewährung schlechthin vor Augen gestellt. Denn insbesondere in Kampfsituation solle man sich nicht nur Gott, sondern stets auch sie vor Augen halten: vil werder ritter, edel

${ }^{34}$ Text: BARTSCH [Anm. 17], Nr. 73. BARTSCH vermutete noch Regenbogen selbst als Verfasser des Textes (S. 176). Jüngere Literatur zu dem Lied ist mir nicht bekannt. EGIDI ([Anm. 2], S. 405) führt es in ihrem Beleganhang zutreffend unter den ermahnenden Sprüchen, ohne jedoch die Spezifika im Darstellungsteil weiter herauszuarbeiten. 
kneht, da bî verlîp, gedenke in der nôt an got, dar nâch an werde frouwen (Str. 4, v. 12f.). Sie sind es, die dann, weil sie hohen muot verleihen, Sieg und Überleben garantieren, $n \hat{o} t$ vertreiben können und somit ganz pragmatisch als leitvertrîb fungieren.$^{35}$ hôhen muot erlangen aber auch die frouwen selbst, wo sie ritterlicher Kampfhandlungen ansichtig werden. Und wenn dann sie selbst $e z$ niht ensehent, da sehent diez in sagen (Str. 2, v. 5), d.h. da bekommen es immerhin andere mit, die es ihnen dann berichten können. Das können dann unter anderem, wie an dieser Stelle gewiß mitzudenken ist ${ }^{36}$ die Spruchdichter sein, die auf Ritterfesten auftreten und diese und ihre herausragenden Teilnehmer anschließend besingen.

Deutlicher schon kommt die selbstreferentielle Dimension in den Liedern von der Macht der Frau in der Herrenlehre mit Mahnung zum Frauenpreis des Dreierbars ${ }^{1}$ Regb/1/545a zum Ausdruck. Gleich zu Beginn wird konstatiert, swer frouwen êret, der sei wol ein salic man und mac selbst mit êren wol bestân (Str. 1, v. 1f.). ${ }^{37}$ Die belebende Macht der frouwen wird dann noch einmal in zwei Richtungen hin weiter aufgefächert und konkretisiert. Zum einen sollen die hochwirdigen manne algelîche (Str. 1, v. 9) sich für die êre der frouwen mit ihrem eigenen Schwert ins Zeug legen (vgl. Str. 2, v. 3f.), weil nicht nur ihr eigenes, sondern unser aller trôst und heil an reinen frouwen lît (Str. 1, v. 12) insofern die Gottesmutter Maria, das Leitbild aller frouwen, für uns alle als Heilsstifterin fungiert (vgl. Str. 1, v. 7, und Str. 2, v. 12). Zum anderen erfährt der Grundgedanke der von Frauen garantierten Bewährung im ritterlichen Kampf eine gewichtige poetologische Konkretisierung. Das sprechende Ich selbst nämlich tritt nun mit seinem Lied ebenfalls in der Rolle des Kämpfers für die frouwen auf, um auf diese Weise den Nachweis ihrer Preiswürdigkeit exemplarisch im

${ }^{35}$ Str. 3, v. 1-13: man sol von erste an got gedenken in der nôt, dar nâch gedenke an die süezen mündel rôt und an ir edeln minne, diu verjagt den tôt hin von der werden helde lip und gebent hôchgemuiete.

${ }^{36} \mathrm{Zu}$ den Sprüchen des Tonerfinders Regenbogens selbst anläßlich des Rostocker Ritterfestes von $1311 \mathrm{vgl}$. SCHRÖDER [Anm. 2], S. 183-190.

${ }^{37}$ Text: BARTSCH [Anm. 17], Nr. 74. Auch hier vermutete BARTSCH noch Regenbogen selbst als Verfasser (S. 176). EGIDI [Anm. 2], S. 405, listet es im Beleganhang unter den ermahnenden Sprüchen (»mit Frauenpreis«, entsprechend auch S. 410 unter "Frauenpreis«); vgl. dort ferner S. 208 Anm. 730 und S. 212 Anm. 748 für Traditionshintergründe einzelner Begründungen (das mariologische Argument, das prolesArgument) des Frauenpreises. Die Abweichung in der Strophenordnung im Heidelberger Cpg 5 beruht ebenso wie der Stollentausch in der jüngeren Drucküberlieferung auf schriftlichen Eingriffen und darf mit einer unfesten Vortragspraxis nicht in Verbindung gebracht werden: BALDZUHN [Anm. 2], S. 274 und S. 443f. 
Lobpreis-Wettstreit zu erbringen. Swer kempft durch frouwen êre oder noch kempfen wil, der trete von dem kreiz zuo mir biz ûf daz zil, fordert das Ich in v. 5f. der dritten Strophe ein impliziertes Gegenüber auf. Es zitiert damit das Interaktionsmuster des Sängerwettstreits herbei. In diesem Rahmen avanciert das Lied des Sängers selbst zum Kampfplatz und Schauplatz höfischer Interaktion. Frauen erretten dann sozusagen nicht mehr >nur< vor dem Tod, wie im oben erwähnten Lied ${ }^{1} \mathrm{Regb} / 1 / 541$, sondern garantieren nun gleichsam das Überleben des höfischen Sangspruchdichters als Kunstmeister. Die Preiswürdigkeit der Frauen gründet in ihrer Funktion als Zentrum und Movens höfischer Lebensart; diese ihrerseits manifestiert sich im Frauenpreis des Liedvortrags in actu.

Der Übertrag der Vorstellung eines als de facto realisierbar imaginierten Wettkampfs unter bewaffneten Rittern in den Liedvortrag des Sängers stellt perzeptionstheoretisch einen komplexen Vorgang dar, dessen theoretische Modellierung noch aussteht. Sie dürfte einigen Aufwand erfordern. Auf jeden Fall wertet dieser Übertrag den Liedvortrag durch Anschluß an ein gemeinhin akzeptiertes, besonderes prestigiöses höfisches Handlungsmuster ganz beträchtlich, nämlich zur höfischen Kunstleistung sui generis auf: Der Liedvortrag wird als eine kollektive Vollzugsform höfischer Lebenspraxis und Geselligkeit von eigenem Recht etabliert. Hält man sich diese Aufwertung bewußt, tritt weiterhin ein bedeutsamer Wandel in der kommunikativen Grundstruktur des Vortrags von Sangsprüchen und Meisterliedern deutlicher hervor. Die Wahrnehmung des Publikums wird nämlich insgesamt stärker auf den Vortrag selbst fokussiert als auf die unmittelbar didaktischbelehrende Auswertbarkeit des Gesagten. Das tritt gerade in jenen Liedern von der Macht der Frau deutlich hervor, in denen das dargestellte Verhalten der Frauen, statt zu Lob und Preis anzuregen, zu Tadel oder doch wenigstens kritischer Stellungnahme herausfordern könnte. Diese Kritik kann dann nämlich durchaus in den Hintergrund treten. In den Vordergrund tritt demgegenüber die Unterhaltungs- und Darstellungsleistung des Sängers, die dem Publikum wichtiger als die unmittelbare Anbindung des von ihm Besprochenen an kollektive Wertmaßstäbe der höfischen Gesellschaft im Sinne einer >Ästhetik der Identität< wird. ${ }^{38}$ Damit entsteht ein Freiraum, gerade auch die negative Macht der Frauen, nämlich die durchaus nicht des Lobpreises würdige list des weiblichen Geschlechts, breiter in den Mittelpunkt des Liedes zu stellen,

${ }^{38}$ JURIJ M. LOTMAN: Die Struktur literarischer Texte, übersetzt von RoLF-DIETRICH KEIL. 4. Aufl. München 1993 (UTB für Wissenschaft 103), S. 404-419. 
ohne daraus einsinnig allein paränetisches Kapital schlagen zu müssen. Vielmehr wird bereits die Darbietung und Entfaltung des Themas als solches goutiert - eine wichtige Voraussetzung für das kürzere weltliche Erzähllied, das im 14. Jahrhundert aufkommt. ${ }^{39}$

Weibliche list wird vorzugsweise dann zum Hauptthema ganzer Lieder, wenn von ihr unstatthafter Gebrauch gemacht wird, der zu unstaete und untriuwe führt. Die belehrenden Schlüsse, die aus dem Dargelegten letztlich gezogen werden, sind jedoch von unterschiedlicher Reichweite. Deren Abstufungen dürfen hier keinesfalls übersehen werden, da nicht bereits das Thema als solches, sondern erst seine Funktionalisierung weiterführende Differenzierungen erlaubt. Ein zweifelsohne als solches bereits konzipiertes dreistrophiges bîspel-Lied stellt die Naturbeobachtung vor Augen, daß die Störchin, als besonders hintertriebenes Tier, nach genossener falscher minne in einem verborgenen Quell ihren Körper zu reinigen pflegt, der Storchenmann hingegen, kommt er ihr gleichwohl auf die Schliche, sogleich den Rat der Mitstörche einholt, um über sie zu Gericht zu sitzen und sie dann durch Bisse strafen zu können ('Regb/1/509: Diu storkinne diu hât den art nâch irme sit) ${ }^{40}$ Das wird nun aber keineswegs einseitig misogyn gegen alle Frauen schlechthin sowie in die Warnung an die Männer gewendet, besonders achtsam zu sein - oder auch einseitig in eine Warnung der Frauen vor Untreue und Strafe. Selbst die Möglichkeit, sich als Vortragender eines solchen Liedes immerhin als Ratgeber beider Zuhörergruppen zu profilieren, wird allenfalls angedeutet. Vielmehr wird zum Schluß der êre und guotes rîche sowie der junge man gemahnt, in sich zu gehen, ob er denn eigentlich selbst triuwe gewesen sei. Gezielt ist also vor allem auf die Notwendigkeit, in einem bereits als rechtlich verbindlich vorgestellten Eheverhältnis von Mann und Frau doch auf beiden Seiten in triuwe zu handeln. Den Gedanken der Wechselseitigkeit betont, in Anlehnung an das bekannte Sprichwort, entsprechend auch der Schlußvers des Liedes: swaz du niht wilt von ir enphân, des soltu sie erlâzen (Str. 3, v. 13). ${ }^{41}$ Das bîspel selbst gäbe zwar reichlich Anlaß zum Ausbau

${ }^{39}$ Eine zusammenhängende Untersuchung des Typs steht aus. Vgl. einstweilen die Hinweise bei StackmanN [Anm. 16], S. 30-32, sowie bei SCHANZE [Anm. 3], Bd. 1, s. Reg. s.v. »Erzählen«.

${ }^{40}$ Textausgabe: BARTSCH [Anm. 17], Nr. 58. Zu Echtheit und Alter hat sich bisher nur BARTSCH geäußert: »Auch 56 ist unecht, aber noch aus der ersten hälfte des 14 . jahrhunderts; ebenso 52 [...] und 58 , das von einem mitteldeutschen verfaßer herrührt« (S. 176). EGIDI berücksichtigt das Lied nicht.

${ }^{41} \mathrm{Vgl}$. Thesaurus proverbiorum medii aevi. Lexikon der Sprichwörter des romanischgermanischen Mittelalters. Begründet von SAMUEL SINGER. Hg. vom Kuratorium Sin- 
einer Konfliktkonstellation; die aber wird, statt auf die Spitze getrieben, eher ausgleichend, eher temperierend unterlaufen. Und so geschieht das durchaus häufiger.

Das neunstrophige Erzähllied ${ }^{1}$ Regb/1/502a von Filius bilde, dar inne man swuor, ${ }^{42}$ setzt zunächst mit einer Klage um verlorene state und triuwe ein - in diesem Zusammenhang fallen die Namen Frauenlobs und Regenbogens, des Trojaners Paris sowie von Tristan und Isolde - und berichtet dann von der vom Zauberer Vergil geschaffenen bocca della verità und wie deren Fähigkeit, Lügnern die hineingelegte Hand abzubeißen, von einer ehebrecherischen römischen Kaiserin ganz nach Art der Isolde-List vor den Augen ihres Mannes umgangen wird. Dem Mann ist auf einem Feldzug als äußerem Zeichen der Fehltritte seiner daheimgeblieben Frau ein stattliches Horn auf dem Kopf gewachsen. Er kehrt sogleich mit seinem ganzen Heer um und will es jetzt aber wissen, verlangt die Treueprobe an der Vergil-Maschine. Die Kaiserin indes läßt den Geliebten als alles und jeden besinnungslos umarmenden Irren auftreten und kann so schadlos die Probe bestehen: Nur in den Armen des Kaisers und dieses Irren habe sie gelegen. Gegen Frauen-list ist selbst ein Kaiser mit einem ganzen Heer machtlos, wird konstatiert - wiederum ohne daß der Verfasser daraus abwertende Schlüsse gezogen sehen will. Die Frau wird in Konsequenz vielmehr zur Selbstdisziplinierung durch innere huote aufgerufen $(E z$ enwart bezzer huote nie ûf erden wane die ein reinez wîp ir selber tuot: Str. 8, v. 9f.) - und die kann dann, wo realisiert, wieder allen Anlaß zum Frauenpreis geben (vgl. Str. 8, v. 11-13: ein reinez wîp die sol man loben vür allez guot ...). Der Einsatz des letzten Abgesangs

ger der Schweizerischen Akademie der Geistes- und Sozialwissenschaften. Berlin/New York 1995-2002, Bd. 12, S. 45-47.

${ }^{42}$ Textausgabe: BARTSCH [Anm. 17], Nr. 55 (nach Handschrift k). Für Nachweise zu weiteren Abdrucken/Ausgaben auf der Grundlage der reicheren späteren Drucküberlieferung, die nachstehend nicht hinzugezogen ist, siehe den RSM-Artikel, zur Beurteilung der Abweichungen der Drucke von der Strophenordnung von k ebd. zu ${ }^{\text {'} F r a u / 1 / 502 b ~ s o w i e ~ B A L D Z U H N ~[A n m . ~ 2], ~ S . ~ 268 . ~ I n ~ E G I D I s ~ B e l e g u ̈ b e r s i c h t ~ e r s c h e i n t ~}$ das Lied S. 414 unter den Ehestrophen »mit Berührung zum Liebesdiskurs, d.h. mit höfischem Vokabular« und wird näher als »Meisterlied über listige Ehebrecherin, mit Minne-Exempeln, Ermahnung und Frauenpreis « charakterisiert. S. 83 Anm. 379 dient es EGIDI als ein Beleg unter anderen für eine sich andeutende Verknüpfung von Eheund Liebesdiskurs im meisterlichen Lied. Zu Alter und Echtheit bisher wiederum nur BARTSCH: »Unecht dagegen ist zunächst 55, eine bearbeitung der Virgiliussage durch einen mitteldeutschen dichter, der gleich im eingange Frauenlob und Regenbogen als ältere dichter nennt: doch ist er selbst wohl nur wenig jünger als sie, vielleicht noch ihr zeitgenoße, der sie überlebte« (S. 176). 
Durch frouwen willen gschiht vil âventiure, durch frouwen willen wirt vil manic man gemeit, durch frouwen willen komet man in arebeit, diu reinen wîp vertrîben künnent herzeleit:

wîp liep, wîp zart, wîp hœchste fruht, wîp hôchgeborn gehiure.

stellt vielmehr die durchaus vielfältigen Wirkungen und damit gerade die Ambivalenz der weiblichen potestas heraus, darunter bezeichnenderweise an erster Stelle, daß durch frouwen willen gschiht vil âventiure. âventiure meint hier nicht nur das Sujet, sondern auch das Erzählen selbst: Das eigentliche Anliegen des Liedes liegt darin, über das Erzählen von der list der Frauen sich noch einmal überhaupt klassische Leitfiguren höfischen Lebens und höfischer Literatur vergegenwärtigen zu können. Daher bleibt die Klage in der Eingangsstrophe über die vergangene Zeit, in der noch state geherrscht habe (Str. 1, v. 9: Ach stcete liebe diu ist gar verdorben), auch ambivalent, fehlt ihr die Durchschlagskraft. Dem Verweis auf das einschlägige state-Exempel von Tristan und Isolde geht die Nennung des Trojaners Paris noch voran, der nicht einfach nur als Negativexempel - er zertrante stater minne bant (v. 6) - herbeizitiert wird, sondern für den ebenso betont werden kann, daß er manheit [...] vil begangen hât durch liebe und ouch durch leide (v. 4). Die einleitende Nennung Frauenlobs und Regenbogens zu Beginn des Liedes - Von âventiure und ouch von ritterlîcher tât, waz. Frouwenlop und Regenboge gesungen hât! (v. 1f.) - erscheint von daher programmatisch: Die beiden haben eben nicht nur speziell von state gesungen, deren Verlust im folgenden alleine zu beklagen wäre, sondern überhaupt von âventiure. Hier schließt das sprechende Ich mit seiner eigenen âventiure genereller an die literarische Tradition an. Die list der Frauen gibt dazu lediglich den Anlaß.

Im Rahmen des übergeordneten Interesses am unterhaltsamen Erzählen als solchem lassen sich dann selbst derbere Erzählstoffe zur Sprache bringen. In dem fünfstrophigen Erzähllied ${ }^{1} \operatorname{Regb} / 1 / 539$, das der Rubrikator der Kolmarer Liederhandschrift, die allein das Bar überliefert, Ander funve wie ein fraw ein forcz liess überschreibt, ${ }^{43}$ tritt das ausgleichende Umgehen der einfachen Konfrontation der Geschlechter, das Interesse am Erzählen selbst, gerade deshalb so deutlich hervor, weil die geschilderte list der Frau hier nun wirklich für misogyne Vereindeutigung allen Anlaß gäbe. Der Mann tadelt einen olfaktorischen

\footnotetext{
${ }^{43}$ Textausgabe: BARTSCH [Anm. 17], Nr. 72. BARTSCH, der sich bisher als einziger zu diesem Lied geäußert hat, nimmt einen mitteldeutschen Verfasser an; er habe bereits nicht mehr zu Lebzeiten Regenbogens gedichtet (S. 176).
} 
>Ausrutscher< der Ehefrau über die Maßen erbost, obwohl er selbst sich in diesem Punkt nie Zwang anzutun pflegte. Die Frau kann die wüste Schelte des Mannes schlau zu ihrem Vorteil wenden: Sollte sie selbst auch nur noch ein einziges Mal von ihrem Mann einschlägig hören oder riechen die wîle daz wir bî einander sollent leben (Str. 1, v. 10), will sie sich dann zur Bestrafung des Mannes von einem anderen lâzen minnen (v. 13). Ein grôz gerummel im bûche des Gatten (Str. 2, v. 11) läßt es dazu erwartungsgemäß kommen. Den zwei Schlußtrophen ist das nun aber keineswegs Anlaß, das doch offenbar von vornherein vorhandene falsche Minneverlangen der Frau zu schelten. Wider Erwarten werden vielmehr sehr ausgewogen sowohl die Männer allgemein angehalten, nicht jede Kleinigkeit maßlos hochzuspielen, sich doch selbst in huote (Str. 4, v. 5) zu üben, als gleichermaßen auch die Frauen, in zühten zu leben (Str. 5, v. 4). Denn zuht êrt ûf erde alzît eben beide, man unde frouwen, und ist ein anhap aller freuden hie und dort (v. 9f. [Hervorhebung von mir, M. B.]). Die erzählte Geschichte und ihre didaktische Funktionalisierung stehen in einem grotesk anmutenden Mißverhältnis zueinander. Es ist kaum zureichend aus einer nach wie vor gültigen Erwartung an die Gattung zu erklären, partout belehrend an einen höfischen Komment - hier die zentrale Bedeutung von zuht, die als Wert im Eingangsvers des Liedes ja früh heraus gestellt wird (Es saz ein frowe gar zühticlîch bî irem man ... [Str. 1, v. 1]) - zu erinnern, die sich noch einmal durchsetzte. Die Erwartung wird ja nicht nur einfach aufgegriffen und ihr Genüge getan. Man müßte eher von einer Parodie der Gattungserwartung sprechen, sollte sich dann aber bewußt halten, $\mathrm{da} ß$ auch diese nur eine besondere Variante der Selbstverständigung der höfischen Gesellschaft darstellt. Diese versteht sich eben als besondere Gruppe nicht schlicht im Medium der in den Liedern propagierten und geteilten besonderen Werte (zuht), sondern erfährt sich und grenzt sich ab als besondere Gemeinschaft, weil sie über das Medium Sangspruch selbst Bescheid weiß. Das Erzähllied ${ }^{1}$ Regb/1/539 zieht also lediglich ein anderes Darstellungsregister als das Erzähllied ${ }^{~} \mathrm{Regb} / 1 / 502 \mathrm{a}$, dokumentiert ansonsten aber wie dieses eine deutliche Literarisierung der Gattung und ihres höfischen Publikums im 14. Jahrhundert.

Weibliches list-Handeln steht auch im Zentrum des allein spätüberlieferten - nämlich in k 281 und in der 1451/52 geschriebenen >Parzival<-Handschrift $\mathrm{G}^{\sigma}$ - Siebenerbars ${ }^{1}$ Regb/1/527ab in der Briefweise. ${ }^{44}$

\footnotetext{
${ }^{44}$ Textausgabe: BARTSCH [Anm. 17], Nr. 69. BARTSCHs Datierungsvorschlag (S. 179: »nicht früher als dessen [d.h. des 14. Jahrhunderts, M.B.] ausgang «) ist in der Richtung sicher zutreffend. Bei EGIDI [Anm. 2] ist das Bar nicht aufgeführt.
} 
Es erzählt in sieben Strophen von der reine [n] meit (Str. 1, v. 5) Lunete am Artushof, die dort aufgrund von ihr extensiv geübter edel milte (Str. 1, v. 4) geschmäht wird, indes alle Frauen des Hofes als ehrlos entlarven kann. Das gelingt ihr mithilfe der Mantelprobe, d.h. mit einem prächtigen Zaubermantel, den sie schlau zunächst an sich selbst exponiert, den dann alle Damen haben wollen, der aber keiner paßt. Einzig die sehr junge Frau des ältesten Ritters am Hofe überhaupt ziert er, weil allein sie, worüber Lunete Artus schließlich aufklärt (Str. 7), ihrem ritter stets die Treue gehalten habe. Neben dem Frauenlist-Thema sind es die Verarbeitung höfischer Erzählstoffe, die Herausstellung der milte Lunetes, die besonders dem auf Entlohnung durch wechselndes Publikum angewiesenen Berufsdichter wichtig gewesen sein muß, die Betonung der Werte state und triuwe und nicht zuletzt der Auftritt des Sängers als Erzähler, die das vorliegende Bar an die bis hierher skizzierte Liedtradition der späten Sangspruchdichtung/frühen Meisterlieddichtung des 14. Jahrhunderts anschließen. Andererseits setzt es sich von den einschlägigen Liedern 'Regb/1/502a, 509, 539, 541, 545a verschiedentlich ab. So wächst der textinternen Auftrittssituation keinerlei poetologische Valenz mehr zu. Das Text-Ich tritt wesentlich nur als Erzähler auf, der nahezu ganz durch das Erzählte selbst, durch seine Figuren, v.a. durch Lunete, spricht, und es profiliert sich entsprechend nirgends auch nur ansatzweise zusätzlich als Wettkämpfer.

Das textintern explizierte Publikum von ${ }^{1}$ Regb/1/539, und wohl auch das für ${ }^{1} \mathrm{Regb} / 1 / 527 \mathrm{ab}$ erwartete, umfaßt selbstverständlich immer noch Mann und Frau gemeinsam, damit potentiell die gesamte Hofgemeinschaft. ${ }^{45}$ Erst ein letztes Meisterlied der die Macht der Frau ins Zentrum stellenden Liedgruppe zögert nicht mehr, allein noch den Mann anzusprechen ('Regb/3/15: Der wurffel und die irren frauen haben paid ainen muet) ${ }^{46}$ Überdies warnt es ihn ganz einsinnig vor der Schlechtigkeit der Frauen. Wie das Würfelspiel eine eminent unverlässliche Angelegenheit sei, ebenso seien es die Frauen, auf die man sich ebensowenig verlassen sollte. Hier greifen wir kaum lediglich ein anderes Register, das im selben zeitlichen Umfeld wie die vorgestellten, kom-

\footnotetext{
${ }^{45}$ Vgl. Str. 4, v. 1 Diz bîspel sollent merken hie die werden man und Str. 5, v. 12f. her umbe, ir reinen frouwen, ir solt al zît vort die zuht bî iu behalten vast.

${ }^{46}$ Textausgabe: Wunderle [Anm. 2], Nr. 36 (zit.) und BARTSCH [Anm. 17], Nr. 199. Entgegen BARTSCH (S. 178: „ein erzeugniss späterer zeit, aber wohl noch aus dem 14. jahrhundert «) verortet WUNDERLE in ihrem Kommentar S. 418f. das Bar - sicher zu Recht - erst »vor dem gesellschaftlichen Hintergrund des 15. Jh.[s]« (S. 418). Bei EGIDI [Anm. 2] wird das Bar unter den ermahnenden Minnesprüchen S. 405 aufgeführt.
} 
plexer angelegten Erzähllieder lediglich für ein anderes Publikum gezogen worden wären, sondern tatsächlich erst eine spätere Ausformungsschicht. Von poetologischer Reflexion findet sich keine Spur. Kaum zufällig ist dieses Lied auch erst in der 1532/33 geschriebenen Heidelberger Meisterliederhandschrift $\mathrm{p}$ überliefert. ${ }^{47}$

\section{Objektiver Frauenpreis}

Eine vierte Gruppe bilden Sprüche und Lieder, die sich schwerpunktmäßig auf den objektiven Frauenpreis verlegen, also darauf verzichten, die Preiswürdigkeit der Frau zusätzlich in der eigenen Erfahrung des sprechenden Ich als selbst von der Minne betroffene Sprecherinstanz zu verankern. Hierher sind das Dreierbar ${ }^{1} \operatorname{Regb} / 2 / 55 \mathrm{a}$ im Grauen Ton aus >Liebhard Eghenvelders Liederbuch< mit fragmentarischer Parallele die Textaufzeichnung wurde B1.344ra inmitten der Eingangsstrophe abgebrochen - in der $>$ Kolmarer Liederhandschrift $<\left({ }^{1} \operatorname{Regb} / 2 / 41 a\right)^{48}$ sowie die vier Bare ${ }^{1} \operatorname{Regb} / 4 / 563 \mathrm{a}, 589 \mathrm{a}, 617 \mathrm{a}$ und 621a im Langen $\operatorname{Ton}^{49} \mathrm{zu}$

${ }^{47}$ Vgl. zur Handschrift RSM, Bd. 1, S. 177 (mit weiterer Literatur).

${ }^{48}$ Textabdruck des bisher unedierten Liedes unten im Anhang 2. 'Regb/2/41a bzw. 55a sind bei EGIDI [Anm. 2], S. 410, unter den Frauenpreis-Strophen gelistet, werden aber nicht weiter besprochen. Auch HELMUT LOMNITZER rubriziert das Lied als Frauenpreis: Liebhard Eghenvelders Liederbuch. Neues zum lyrischen Teil der sogenannten Schratschen Handschrift. ZfdPh 90 (1971) 190-216, hier S. 205. Stützen kann sich diese Zuordnung schon auf den Rubrikator von k, der die Strophen Aber iij ein prys liet überschrieb. Vgl. neben den Angaben in den beiden RSM-Artikeln zu den zwei Liedaufzeichnungen jetzt auch noch RETTELBACH [Anm. 2], S. 127, und BALDZUHN [Anm. 2], S. 285.

49 'Regb/4/563a: vgl. für den Text Schulz [Anm. 2], S. 66f. (mit kurzem Kommentar dazu S. 131f.) und darüber hinaus SCHANZE [Anm. 3], Bd. 1, S. 86; BALDZuHN [Anm. 2], S. 304; EGIDI [Anm. 2], S. 83 Anm. 379, S. 405 (unter "Ermahnende Minnesprüche«, dort stichwortartig näher qualifiziert als "Schelte; mit Frauenpreis; Ehespruchstrophen [...]; mit Ich-Rede«), S. 410 (unter »Frauenpreis«, jedoch »mit Ermahnung «), und S. 414 (unter den »Ehestrophen«, näherhin den »Strophen mit Berührung zum Liebesdiskurs, d.h. mit höfischem Vokabular«). Vgl., da Str. 2 und 3 auch in $\mathrm{k} 438,5$ und 4 bezeugt sind, zudem unten die Hinweise zu ${ }^{1} \mathrm{Regb} / 4 / 589 \mathrm{a}$.

${ }^{1}$ Regb/4/589a: vgl. für den Text SchULz [Anm. 2], S. 68-70 (mit kurzem Kommentar dazu S. 132) sowie ebd. S. 244 und S. 247 und darüber hinaus SCHANZE [Anm. 3], Bd. 1, S. 86; BALDZuHN [Anm. 2], S. 305f.; EGIDI [Anm. 2], S. 410 (in der Sparte »Frauenpreis«). Vgl., da Str. 4 und 5 auch in $\mathrm{k} 414,3$ und 2 bezeugt sind, zudem oben die Hinweise zu 'Regb/4/563a.

'Regb/4/617a: vgl. für den Text vON DER HAGEN [Anm. 15], Bd. 3, S. 468k sowie darüber hinaus BALDZUHN [Anm. 2], S. 297 und SCHANZE [Anm. 3], Bd. 1, S. 86 (jeweils zur Parallelüberlieferung der Eingangsstrophe von $f$ in $k$ 358,2) sowie EGIDI [Anm. 2], S. 405 (Str. 2 und 3 in der Gruppe »Ermahnende Sprüche«, aber »mit Frauenpreis «, entsprechend noch einmal S. 410 unter »Frauenpreis «). 
stellen. Von letzteren überschneiden sich die Bare ${ }^{1}$ Regb/4/563a, 589a, und 621a mehrfach im Strophenbestand. Das ist am einfachsten tabellarisch zu veranschaulichen:

\begin{tabular}{|c|c|c|c|}
\hline & & & ${ }^{1} \operatorname{Reg} b / 4 / 621 a, 3$ \\
\hline${ }^{1} \operatorname{Regb} / 4 / 589 \mathrm{a}, 1$ & & & \\
\hline${ }^{\prime} \operatorname{Regb} / 4 / 589 \mathrm{a}, 2$ & & & \\
\hline${ }^{\prime} \operatorname{Regb} / 4 / 589 \mathrm{a}, 3$ & $=$ & & ${ }^{1} \operatorname{Reg} b / 4 / 621 \mathrm{a}, 2$ \\
\hline${ }^{1} \operatorname{Regb} / 4 / 589 a, 4$ & $=$ & 'Regb/4/563a,3 & \\
\hline${ }^{1} \operatorname{Regb} / 4 / 589 \mathrm{a}, 5$ & $=$ & $\begin{array}{l}{ }^{1} \operatorname{Regb} / 4 / 563 \mathrm{a}, 2 \\
{ }^{1} \operatorname{Regb} / 4 / 563 \mathrm{a}, 1\end{array}$ & $={ }^{1} \operatorname{Reg} b / 4 / 621 \mathrm{a}, 1$ \\
\hline
\end{tabular}

Es wurden in diesen Baren offensichtlich mehrfach alte Einzelstrophen verarbeitet. Neben diesen Baren verarbeitet auch Lied ${ }^{1}$ Regb/4/617a ausweislich seiner Parallelüberlieferung mindestens eine alte Einzelstrophe, denn die Eingangsstrophe erscheint noch einmal als Mittelstrophe von ${ }^{1} \mathrm{Regb} / 4 / 508 \mathrm{a}$. Alle vier Bare sind demnach höchstwahrscheinlich noch in einer Phase des Übergangs von der Einzelstrophigkeit der älteren Sangspruchdichtung in die feste Mehrstrophigkeit des meisterlichen Liedes entstanden. Sie dokumentieren eine Form der Liedproduktion, der zwar Mehrstrophigkeit bereits die Regel geworden ist, nicht jedoch unabdingbares Gebot auch schon die alleinige Einmalverwendung einer Strophe. In der Folge entstehen in der fraglichen Frühphase meisterlichen Dichtens oft auch noch Lieder, die aus einem Pool frei verfügbarer Strophen zusammengebaut sind, ohne daß deren Verwendung in einem bestimmten Lied die Wiederverwendung in einem weiteren - wie dann beim späteren Meisterlied - schon ausgeschlossen hätte. Aus der Varianz ihrer Strophenordnung läßt sich für alle vier Bare, obwohl sie alle erst spät, d.h. in Handschriften des 15. oder 16. Jahrhundert überliefert sind, eine Datierung noch in das 14 . Jahrhundert ableiten. Diese ihrerseits paßt prinzipiell zur potentiellen Tiefe der zeitlichen Schichtung, mit der man für die Textbestände der an ihrer Überlieferung beteiligten Handschriften - der >Kolmarer Liederhandschrift $<k$, der >Weimarer Liederhandschrift $<\mathrm{f}$ und der $>$ Wiltener Handschrift $<\mathrm{w}-$ von Fall zu Fall rechnen muß. ${ }^{50}$

\footnotetext{
${ }^{1}$ Regb/4/621a: vgl. für den Text SchUlz [Anm. 2], S. 109f. (mit kurzem Kommentar dazu S. 142f.; s. auch S. 244-247, 249, 258) sowie darüber hinaus EGIDI [Anm. 2], S. 410 (Str. 3 im Beleganhang unter »Frauenpreis « gelistet). Vgl., da die ersten beiden Strophen auch in k 438,5 und 3 bezeugt sind, zudem oben die Hinweise zu ${ }^{1} \mathrm{Regb} / 4 / 589$ a sowie zur ersten Strophe, die in k 414 die Mittelstrophe bildet, oben die Hinweise zu ${ }^{1}$ Regb/4/563a.

${ }^{50} \mathrm{Vgl}$. für die Vorlagenverhältnisse von k zuletzt BALDZUHN [Anm. 2], S. 471-486, für f BURGHART WACHINGER: Von der Jenaer zur Weimarer Liederhandschrift. Zur Cor-
} 
Obwohl im Strophenbestand nur unverändert bezeugt, sollte man auch den vollständig einzig aus >Liebhard Eghenvelders Liederbuch< des Wiener Cod. ser. nov. 3344 bekannten Frauenpreis ${ }^{1}$ Regb/2/55a nicht weit von dieser Datierung des alten Strophenpools abrücken.

Mag auch der Liederteil der Handschrift erst um 1431/34 vom damals Hainburger Schulmeister Eghenvelder »nach Vorlagen unterschiedlicher Qualität« zu Papier gebracht worden sein,$^{51}$ geriet dem Schulmeister ja durchaus noch sechter Neidhart und Frauenlob unter die Feder.$^{52}$ Seine Sammlung entfließt keineswegs einzig einem produktiven, lebendigen Liedbetrieb in der unmittelbaren Umgebung. Hier sind speziell im Hinblick auf ihre Meisterlieder zunächst die generellen Überlieferungsverhältnissen der Gattung zu dieser Zeit zu bedenken: In der Breite entstehen Meisterliederhandschriften erst seit dem zweiten Viertel des 15. Jahrhunderts, und auch für sie ist noch nirgends ein bereits geregelter Liedbetrieb im Hintergrund erkennbar, der deutlich auf den städtischen Meistergesang vorauswiese. Hinzu kommt die Entstehung der Eghenvelderschen Sammlung auffallend weit im Südosten des deutschen Sprachraums, der erst im 16. Jahrhundert - dann aber bereits im Kontext des institutionalisierten Meistergesangs - als Trägerraum der Gattung hervortreten wird. Überhaupt vertreten von den 31 Nummern des >Liederbuchs 'gleich ein Dutzend Pseudo-Neidhart bzw. Neidhart ${ }^{53}$ der doch am Rande der meisterlichen Liedtradition steht. ${ }^{54}$ Unter den übrigen 19 Stücken erscheinen zwar 16 in Sangspruchtönen ${ }^{55}$ darunter jedoch bei den Meistersingern ohne Wirkung gebliebene, anonyme Formexperimente ${ }^{56}$ und Töne zwar prominenter Meister, die

pusüberlieferung von Frauenlobs Spruchdichtung. In: Philologie als Kulturwissenschaft. Studien zur Literatur und Geschichte des Mittelalters. Fs. für Karl Stackmann zum 65. Geb. Hg. von LUDGER GRENZMANN u.a. Göttingen 1987, S. 193-207, und für w die Bemerkungen von KARL STACKMANN in: Die kleineren Dichtungen Heinrichs von Mügeln. 1. Abteilung: Die Spruchsammlung des Göttinger Cod. Philos. 21. Hg. von KARL STACKMANN. Berlin 1959 (DTM 50-52), hier Bd. 1, S. CLVIII (meist »aus den trübsten Quellen « schöpfend, aber zugleich »noch um 1500 einen großartigen Text der Bücher 9 und 10 « bietend).

${ }^{51}$ Vgl. zusammenfassend zur Person Eghenvelders HeLmUT LOMNITZER: Eghenvelder, Liebhard. In: ${ }^{2}$ VL, Bd. 2, Sp. 377-379 (das Zitat ebd. Sp. 379), sowie zur Handschrift neben den knappen Angaben im RSM, Bd. 1, S. 298f. (mit weiterer Literatur) v.a. LOMNITZER [Anm. 48].

${ }^{52}$ Vgl. zur Übersicht für Neidhart die Tabelle bei DIETRICH BOUEKE: Materialien zur Neidhart-Überlieferung. München 1967 (MTU 16), S. 43 und für die FrauenlobSprüche die Bestandsübersicht in der GA (STACKMANN/BERTAU [Anm. 4], Bd. 1, S. 57).

${ }^{53}$ Zusammengestellt in: Die Wiener Neidhart-Handschrift w (Österreichische Nationalbibliothek Wien, series nova 3344). Transkription der Texte und Melodien von INGRID BENNEWITZ-BEHR unter Mitwirkung von URICH MÜLLER. Göppingen 1984 (NeidhartMaterialien 2; GAG 147).

${ }^{54}$ HORST BRUNNER: Neidhart bei den Meistersingern. ZfdA 114 (1985), 241-254.

${ }^{55}$ Nr. 1-4, 6f., 17f., 20-22 und 25-29.

${ }^{56} \mathrm{Nr} .18$ auf Bl. $108^{\text {rb-va: }}{ }^{1} \mathrm{ZX} / 510 / 1$ in einem namenlosen Ton. 
aber den Formansprüchen der späteren Meistersinger nicht genügten und von ihnen nicht rezipiert wurden,$^{57}$ sowie Lieder in Tönen, deren Überlieferung ohnedies auffallend breit gestreut ist und über die eigentlichen Meisterliederhandschriften hinausgeht ${ }^{58}$ und von Tonautoren des 13. Jahrhunderts, denen späterhin von den Meistersingern aufgrund ihres weit über das Gemerk hinausreichenden Erfolges ein Sonderstellung zugestanden wird. ${ }^{59}$ Die offenkundige Distanz des >Liederbuchs $<$ zum institutionalisierten Meistergesang hat LOMNITZER sogar veranlaßt, das gesamte Genus des Rügelieds, das in Nr. 21 - ein straffer überschrieben - vertreten ist, nicht erst der Periode des zunftmäßigen Meistergesangs zuzuschreiben, obwohl der Liedtyp in der älteren Forschung gerne als durch und durch meistersingerisch betrachtet wird. ${ }^{60}$ Man wird hier sicher noch einen Schritt über LOMNITZER hinaus gehen können und das vorliegende Lied auch der städtischen Bildungsschicht Hainburgs absprechen, die mit ihm nicht nur als Träger des spätmittelalterlichen Liedes in seinen verschiedenen Facetten, sondern überdies des dezidiert kunst-meisterlichen Wettstreitliedes hervorträte. Wenn dem so wäre, wäre in Eghenvelders >Liederbuch doch sehr viel mehr an einschlägig auf den Meistergesang vorausweisenden Strophen zu erwarten.

Mehr Wahrscheinlichkeit hat für sich, daß ${ }^{1}$ Regb/2/55a Eghenvelder lediglich in seiner Eigenschaft als Schreiber und Sammler in die Feder floß, dem hier Vorlagen zugänglich wurden, die weiter in die Geschichte des meisterlichen Liedes zurückreichen. Im wesentlichen unter dieser besonderen Voraussetzung dürfte auch das unmittelbar anschließende poetologische Lied Nr. 22 ('Pfalz/2a) im Rohrton des Pfalz von Straßburg in das >Liederbuch< eingegangen sein: Seine Ausgestaltung der

${ }^{57}$ Nr. 25 auf Bl.111 11 tb-112 ${ }^{\text {ra }}$ 'Frau/10/500a in Frauenlobs Kurzem Ton. Vgl. LOMNITZER [Anm. 47], S. 211; Helmuth THOMAS: Untersuchungen zur Überlieferung der Spruchdichtung Frauenlobs. Leipzig 1939 (Palaestra 217), S. 31 und S. 89f.; STACKMANN/BERTAU [Anm. 4], Bd. 1, S. 165, sowie den Bestand der im RSM unter ${ }^{1} \mathrm{Frau} / 10$ verzeichneten Lieder.

${ }^{58} \mathrm{Nr} .3,4$ und 7: ${ }^{1}$ PeterA/2/1c in Peters von Arberg [?] Tagweise I, 'Frau/33/1b in der Frauenlob zugeschriebenen Zugweise, 'PeterA/3/1d in Peters von Arberg [?] Tagweise II. Vgl. zu den Echtheitsfragen um die Arberg-Töne zusammenfassend VOLKER MERTENS: Peter von Arberg. In: ${ }^{2}$ VL, Bd. 7, Sp. 426-429. Die Überlieferung der Zugweise charakterisiert knapp RETTELBACH [Anm. 2], S. 285.

${ }^{59} \mathrm{Nr} .6$ und 26: ${ }^{1} \operatorname{ReiBr} / 524 \mathrm{a}$ und ${ }^{\mathrm{R}} \mathrm{ReiBr} / 525 \mathrm{a}$. Vgl. zu Reinmar von Brennenberg die bekannte Stelle im Nürnberger >Schulzettel : Jtem es sol auch kainer kain maistergesang noch maister thon $z u$ nacht auf der gassen singen ausgenummen stück fraw〈en〉 lob prenberger Muscatplut Schiller [...]. (zit. nach dem Faksimile von HAHN [Anm. 11], Bl. 118 $-121^{\mathrm{r}}$, hier Bl. 120 ).

${ }^{60}$ Lomnitzer [Anm. 48], S. 208f., zu 'Wartb/2/515a. Den Text des in Klingsors Schwarzem Ton verfaßten Dreierbars hat ADOLF HolTZMANN nach der Parallelüberlieferung im Heidelberger Cpg 392 abgedruckt: Meistergesänge des XV. Jahrhunderts. Germania 3 (1858) 307-328, hier S. 318. 
Wettstreit-Situation und seine poetologische Ausrichtung ließen LOMNITZER zwar an »Meistergesang reinsten Wassers « denken: ${ }^{61}$ Beides aber kann ebenso für die Frühphase des meisterlichen Liedes reklamiert werden. ${ }^{62}$ Auch zählt Pfalz wohl zu den Meistern bereits des 14. und beginnenden 15. Jahrhunderts und könnte gerade dieses Lied dem Ton sogar seinen Namen verliehen haben. ${ }^{63}$ Speziell ${ }^{1}$ Regb/2/55a wartet mit einer Besonderheit in der Kennzeichnung des Verhältnisses von Lied und Strophe auf - der zweiten und dritten Strophe geht nämlich jeweils noch eigens der Hinweis secundum bzw. tertium voran - , die das $>$ Liederbuch < an dieser Stelle vielleicht noch mit Praktiken eher des 14. als des 15. Jahrhunderts verbindet. ${ }^{64}$ Vom Text des Frauenpreises selbst her schließlich legt ebenfalls nichts eine Entstehung erst aus moderner stadtbürgerlicher Liebesliedpraxis im Umkreis des >Liederbuchs « nahe: »Der Typ des stilistisch stark geblümten Frauenlobs ist durch zahllose Bezeugungen wohlvertraut. ${ }^{65}$

Für die Lieder ${ }^{1} \operatorname{Regb} / 2 / 55 a,{ }^{1} \operatorname{Regb} / 4 / 563 a, 589 a, 617 \mathrm{a}$ und 621a können hier nur einige auffallendste Merkmale benannt werden, die sie mit den bis hierher vorgestellten Ausgestaltungen des Minnethemas verbinden. Das Eingangsstrophenpaar des in k Ein pryslied 5 lied überschrie-

${ }^{61}$ LOMNITZER [Anm. 48], S. 209. Vgl. den nach der Parallelüberlieferung in der Wiltener Handschrift abgedruckten Text bei BARTSCH [Anm. 17], S. 114f.

${ }^{62} \mathrm{Vgl}$. für die Wettstreit-Situation die oben angeführten Beispiele und im Hinblick auf die poetologische Terminologie Michael BALDZUHN: Ein Feld formiert sich. Beobachtungen zur poetologischen Begrifflichkeit in den Tabulaturen der Meistersinger. In: Im Wortfeld des Textes. Hg. von GERD DICKE u.a. Berlin/New York 2006 (Trends in Medieval Philology 10), S. 165-185.

${ }^{63}$ Vgl. GiSELA KORNRUMPF: Mülich von Prag, Pfalz von Straßburg, Albrecht Lesch. Neues zur Überlieferung. ZfdA 106 (1977) 121-137, hier S. 132f.

${ }^{64} \mathrm{Im}$ RSM-Artikel sind diese zwei lateinischen Einträge irrtümlich übersehen. Vgl. zu den verschiedenen Rubrizierungspraktiken in den spätmittelalterlichen Handschriften mit Sangsprüchen und Meisterliedern, die nicht zuletzt in Abhängigkeit vom zeitgenössischen Status von Text- und Tonautorschaft wie vom Stand der Durchsetzung des mehrstrophigen Meisterliedes wechseln, ausführlich BALDZUHN [Anm. 2], S. 69-126. Die Durchzählung der Strophen eine Liedes kann sich vor dem Hintergrund des Barbildungsprozesses im 14. Jahrhundert einem weniger eingespielten Umgang eines Schreibers mit der schriftlichen Aufzeichnungseinheit >Lied verdanken. Das ist allerdings von Fall zu Fall zu prüfen und darf nicht pauschalisiert werden. Denn Durchzählung lediglich zur besseren Orientierung des intendierten Lesers oder zur Selbstvergewisserung des Schreibers ist Schreibern natürlich immer möglich, wie etwa das Beispiel des erst zu Anfang des 16. Jahrhunderts aufgezeichneten Fünferbars ${ }^{1} \mathrm{Regb} / 4 / 656$ in der Hans-Sachs-Handschrift q belegt (s.u. den Textabdruck in Anhang 2). Für 'Regb/2/55a im >Liederbuch` Eghenvelders läßt sich aber erstere Möglichkeit nicht sicher ausschließen.

${ }^{65}$ LOMNITZER [Anm. 48], S. 205. 
benen Bars ${ }^{1}$ Regb/4/589a führt in Fülle literarische Beispielfiguren aus der höfischen Literatur, aus der Wilhelms-Epik und dem >Parzival< Wolframs von Eschenbach auf. Mit ihnen wird erneut belegt, daß, waz heilsam werk der creftenriche, was manheit ie begieng, daz waz dorch werde wyp (Str. 1, v. 2): Die Funktionalisierung der literarischen Tradition für das deklarierte Ritter- und Minne-Ideal verbindet es eng mit Beispielen wie ${ }^{1}$ Regb/4/508a und ${ }^{1}$ Regb/1/502a. Mehrfach wird der Unsagbarkeitstopos in einer Weise verwendet, die auch an die Profilierung des Sängers im Wettstreit denken läßt - so in ${ }^{1} \operatorname{Regb} / 2 / 55 a$, Str. 1 , v. $2 \mathrm{f}$. (dein lob stet hoch gemessen, vnd dich holt nyme volloben kan) und in ${ }^{1}$ Regb/4/563a, Str. 2, v. 5f. (wer mag ein creature wysen, die also wirdiclich gezieret sy mit lop?): siehe dafür oben $\mathrm{zu}{ }^{1} \mathrm{Regb} / 1 / 541$ und ${ }^{1} \mathrm{Regb} / 1 / 545 \mathrm{a}$. Der agonale Anklang des Frauenpreises dürfte auch die Verbindung des Liedes ${ }^{1} \operatorname{Regb} / 4 / 621 \mathrm{a}$ (= w 149), das sich in Str. 1 mit ${ }^{1}$ Regb/4/563a und Str. 1f. mit ${ }^{1}$ Regb/4/589a überschneidet, mit dem Wettstreitgedicht ${ }^{1} \mathrm{Regb} / 4 / 622$ (= w 150) angestoßen haben, das in der ,Wiltener Handschrift < unmittelbar anschließt und u.a. mit der Nennung berühmter Sangspruchdichter - Frauenlob, Heinrich von Ofterdingen, Wolfram von Eschenbach, Walther von der Vogelweide - aufwartet. ${ }^{66}$ Entschieden autoreferentiell richten den Frauenpreis dann Verse wie in ${ }^{1} \mathrm{Regb} / 4 / 617 \mathrm{a}$, Str. 2, v. 16-19 aus (wip, minne du die triuwen man, die sprechen wol in also suezer wis; unt der din lop gebreiten kan, dem selben soltu geben hohen pris), in ${ }^{1} \mathrm{Regb} / 4 / 621 \mathrm{a}$, Str. 3, v. 5-7 (sy tragent auf in eren purde mit also vollem luste, daß ir suesser leib sait allen preysen preises mat), v. 12f. (es ward nie mannes hertz so gar verstainet, von sange[] es erwaichet wol), v. 20-23 (der hat weltleicher freuden hort. des setz ich im mein trew zuo ainem pfandt, daz weibhait frewden ist so vol. urhab der mannes frewd sind sew genannt) und in ${ }^{1} \mathrm{Regb} / 4 / 589 \mathrm{a}$, Str. 3, v. 3-8 (wyp, dorch din wird ist ratten clang, wip, dorch din wird ist harphen unde gygen. wyp, dorch din wirdikeit in oren höret man mynniclicher sußer spruche vil. wyp, durch din wird ist sußer sang, wyp, durch din wird ist grüßen unde nygen). Wiederum führt der Sänger Frauenpreis nicht bloß vor Publikum vor, sondern präsentiert sich sein Sprechen von Frauen und Minne als dem ritterlichen Kampf tendenziell gleichwertiger Kulminationspunkt höfischer Lebensart schlechthin: wyp, durch din wird ist rytterschaft, wyp, durch din wirde hort man helm erclingen ( ${ }^{1}$ Regb/4/589a, Str. 3 , v. 9f.). Hinzu

${ }^{66}$ Der Text der Mittelstrophe des Dreierbars ist abgedruckt bei BARTSCH [Anm. 17], S. 670f. Für die bisher unedierten Strophen Nr. 1 und 3 kann einstweilen nur auf die Inhaltsangaben im entsprechenden RSM-Artikel verwiesen werden. 
kommen Details wie der in ${ }^{1} \mathrm{Frau} / 2 / 55 \mathrm{a}$, Str. 2 , v. 5 (dem ist pas dan chaiser reich mit lanten vnd mit leuten) und in ${ }^{1} \operatorname{Regb} / 4 / 589 a$, Str. 4 , v. 18f. (so wart keyn keyser nie so her, der din vergelten mecht ein cleyn gelyt) verarbeitete Kaisertopos: siehe schon oben $\mathrm{zu}{ }^{1} \mathrm{Regb} / 1 / 5$, v. 11, ${ }^{1}$ Regb/1/511, Str. 3, v. 2, und ${ }^{~} \operatorname{Regb} / 1 / 521$, Str. 3, v. 1, oder auch zu der Kaiserin, die sich Isoldes List zunutze gemacht hat, im Erzähllied ${ }^{1} \mathrm{Regb} / 1 / 502 \mathrm{a}$. Die Eingangsstrophe von ${ }^{1} \mathrm{Regb} / 4 / 563 \mathrm{a}$ mag gar unter direktem Einfluß eines Minnespruchs im Langen Ton Heinrichs von Mügeln entstanden sein, denn hier wie dort tritt die alttestamentarische Figur der israelitischen Königin Jezabel auf. ${ }^{67}$ Von den Sprachmitteln des geblümten Stils wird überdurchschnittlich dicht Gebrauch gemacht; das hat zu Entstellungen des Überlieferten geführt, die den erhaltenen Text stellenweise schwer verständlich machen. Deutlich sichtbar bleibt allerdings der entschiedene Ausgriff des Verfassers in Naturlehre, Kosmologie und Meteorologie, hinter dem Mügelns (und Frauenlobs) Versuche stehen dürften, Minne im Rahmen der Naturtheorie auf neue Weise zu durchdenken. ${ }^{68}$

\section{Authentisierung:}

Das Ich als Minne-Betroffener im subjektiven Frauenpreis

Derart deutliche Anlehnungen an die großen meister des 14. Jahrhunderts wie in ${ }^{1} \mathrm{Regb} / 4 / 563 \mathrm{a}$ sind unter den objektiven Frauenpreissprüchen in Regenlob-Tönen die Ausnahme. Deshalb wird man die auffallendste Neuerung, mit der Minnestrophen und -lieder in RegenbogenTönen aufwarten, den Auftritt des sprechenden Ich als selbst von der Minne Betroffenes, nicht ausschließlich auf Mügelns Minne-Bekundungen - wie STACKMANN sie nennt ${ }^{69}$ - zurückführen, sondern für den Erfolg entsprechender Strophen und Lieder nach Gründen suchen, die über den Einfluß eines einzelnen Euvres hinausgehen und bereits hin-

\footnotetext{
${ }^{67}$ Vgl. Heinrichs von Mügeln Spruch 48 und dazu STACKMANN [Anm. 2], S. 144f.

${ }^{68}$ In Str. 1 wie 2 ist, unter Verwendung gelehrt-anspruchvoll anmutender Begriffe ( $g e$ hilwe, creature, umbesweiff) die Rede von Nebel, Wind, Wolken, Planeten, Firmament, Sonne, Tag und Nacht. Vgl. für den Hintergrund in den Minnestrophen bei Mügeln jetzt HUBER [Anm. 2], S. 97-102. Mügeln selbst nimmt bekanntlich auf den Sangspruchdichter Regenbogen zweimal direkt Bezug: in seinem Spruch 3 (v. If.: In siner langen wise von des himels ort spricht Regenboge. daran sin tichten stet vermort [...]) und in der Verwendung der Paratweise Regenbogens, die später auch unter dem Namen >Grundweise` und >Kurzer Ton< läuft, für drei Strophen seiner >Ungarnchronik< (vgl. ${ }^{1} \mathrm{HeiMü/410:} \mathrm{in} \mathrm{nota} \mathrm{mensurata} \mathrm{Regunspogin} \mathrm{rethoris} \mathrm{que} \mathrm{Paratwyse} \mathrm{dici-}$ tur).

${ }^{69}$ STACKMANN [Anm. 2], S. $148 \mathrm{f}$.
} 
ter Mügelns Strophen selbst stehen. Nur so läßt sich die Breite erklären, in der die nachstehend als >subjektiver Frauenpreis < bezeichneten Texte im untersuchten Ausschnitt erscheinen. Aus dem Regenbogen-Korpus gehören gleich 14 Lieder hierher: in der Briefweise ${ }^{1}$ Regb/1/101, 104a, 510a, 544, 553, 554a, 562, 566a, 572 und 573, im Grauen Ton ${ }^{1} \mathrm{Regb} / 2 / 31 \mathrm{a}$ und $33 \mathrm{a}$, in der Paratweise ${ }^{1} \mathrm{Regb} / 3 / 6$ und im Langen Ton ${ }^{1} \operatorname{Regb} / 4 / 509{ }^{70}$

Sie verbindet im Kern der Kunstgriff, die Preiswürdigkeit der Frau im sprechenden Ich selbst zu verankern, das mit seinen eigenen Erfahrungen für die Berechtigung des Lobes einsteht. Das muß zwar nicht immer über das ganze Lied hinweg geschehen. Mehrfach tritt ein Textsprecher in der ersten Person nur in einzelnen Strophen auf - im Extremfall ${ }^{1} \mathrm{Regb} / 1 / 510 \mathrm{a}$ gar nur in der Eingangsstrophe, auf die in Str. 2-7 dann nur noch der konventionellere objektive Frauenpreis folgt. ${ }^{71}$ Aber indem die Rolle des Liebenden gleich eingangs eingenommen wird, stellt dies alle folgenden, allgemeineren Aussagen unter ein entsprechendes Vorzeichen; auch sie bleiben in der Vortragssituation dem

${ }^{70}$ Ich benutze die Texte in den unten im Anhang 1 angegebenen Ausgaben und Abdrucken von SCHRÖDER, BARTSCH, SCHULZ und VON DER HAGEN sowie speziell ${ }^{1} \mathrm{Regb} / 4 / 509$ im Abdruck von CHRISTOPH PETZSCH: Transzendierendes im hoveliet eines meisters. Euphorion 72 (1978) 344-347. Vgl. für die bisher nicht edierten Texte 'Regb/1/553, 562, 566a Str. 2 und 573 unten Anhang 2. Die Angaben in den RSMArtikeln zur Forschungsliteratur sind verschiedentlich um jüngere Beiträge zu ergänzen. Vgl. für 'Regb/1/104a Str. 3 jetzt auch EGIDI [Anm. 2], S. 410 (unter "Frauenpreis« gelistet), für ${ }^{1}$ Regb/1/510a BALDZUHN [Anm. 2], S. 268 und EGIDI [Anm. 2], S. 208 und S. 212 (zu Str. 4 und 7) und S. 410 (Str. 2-7 unter "Frauenpreis« gelistet), für ${ }^{1} \operatorname{Regb} / 1 / 544$ neben der Ausgabe durch ScHULZ [Anm. 2], S. 59f. den kurzen Kommentar ebd. S. 130 und S. 240, 243, 248-250 und 255, für ${ }^{1}$ Regb/1/554a MANFRED KERN: Hybride Texte - wilde Theorie? Perspektiven und Grenzen einer Texttheorie zur spätmittelalterlichen Liebeslyrik. In: Deutsche Liebeslyrik im 15. und 16. Jahrhundert [Anm. 8], S. 11-45, hier besonders S. 21-26 und S. 40-42, für ${ }^{1}$ Regb/1/566a Str. 2 EGIDI [Anm. 2], S. 237 und S. 410 (unter »Frauenpreis«, jedoch mit »Preis als Ich-Rede der Frau « gelistet), für ${ }^{1} \mathrm{Regb} / 2 / 31$ a neben der Ausgabe durch SCHULZ [Anm. 2], S. 61-63 ebd. den kurzen Kommentar S. 130f. sowie S. 243, 247, 249 und 251, ferner BALDZUHN [Anm. 2], S. 282-285 und S. 461f. sowie EGIDI [Anm. 2], S. 410 (unter »Frauenpreis«, und zwar »z.T. mit Ich-Rede; Str. 4: Preis der Geliebten «), für 'Regb/2/33a neben der Ausgabe durch Schulz [Anm. 2], S. 64f. den Kommentar ebd. S. 131 und S. 251 sowie BALDZUHN [Anm. 2], S. 282-285 und S. 461f., für ${ }^{1} \mathrm{Regb} / 3 / 6$ neben der Ausgabe durch SCHulz [Anm. 2], S. 71 auch den kurzen Kommentar ebd. S. 133 und ebd. S. 243 sowie für 'Regb/4/509 EGIDI [Anm. 2], S. 410 (Str. 3 unter »Frauenpreis gelistet, und zwar »mit kurzer Ich-Rede und Preis der Geliebten $\ll)$.

${ }^{71} \mathrm{Vgl}$. Str. 1, v. 5-8: Sô sî mîn trôst für trûren reiner wîbe gruoz, sô tuo mir reiner wîbe liebe sorgen buoz. in rehter gir, in ganzer lust ich wünschen muoz daz frouwen schœene sî mîn heil, swar ich der lande kêre. 
Text-Ich zuschreibbar; es scheint also lediglich eine besondere Erfahrung durch eine verallgemeinernde Sprechweise zu stärkerer Geltung gebracht werden zu sollen. ${ }^{72}$ In der Mehrzahl der Lieder allerdings wird die Imagination des von der Minne betroffenen Textsängers ohnehin über alle Strophen hinweg durchgehalten. ${ }^{73}$

Das Text-Ich auch in Sangspruchstrophen als minnebetroffenes auftreten zu lassen, ist nicht neu, sondern aus der älteren Gattungstradition bereits bekannt. ${ }^{74}$ Hieran konnte man prinzipiell anknüpfen. Die einschlägigen Strophen in Regenbogen-Tönen sind daher keineswegs erst spät bezeugt, sondern finden sich schon in der Vorauer Handschrift zu Anfang des 14. Jahrhunderts ( ${ }^{1}$ Regb/1/101) und im $>$ Möserschen Fragment< ( $\left.{ }^{1} \mathrm{Regb} / 1 / 104 \mathrm{a}\right){ }^{75}$ das um 1400 noch vor dem breiteren Einsatz der Meisterliederhandschriften entsteht, von denen es ferner, unter vielem anderen, die Aufnahme von Minneliedern Frauenlobs trennt. ${ }^{76} \mathrm{Zu}$ dem führt unter den erst aus dem 15. Jahrhundert bezeugten Liedern der Vergleich mit den Überlieferungsparallelen mehrfach auf Formen von Strophenordnungsvarianz, die noch in die Phase der unfesten Mehrstrophigkeit zurückweisen ( ${ }^{1} \mathrm{Regb} / 1 / 510 \mathrm{a}$ [erst aus k], 'Regb/1/566a [aus w, aber mit Überschneidungen zum >Möserschen Bruchstück< und k], ${ }^{1}$ Regb/2/31a und 33a [beide erst aus k]) ${ }^{77}$ Vereinzelt treten Reminiszenzen an die wîp-Etymologie Frauenlobs hinzu $\left({ }^{1}\right.$ Regb/1/104a, Str. 3, v. $1,{ }^{1}$ Regb/2/31a, Str. 6, v. 5) ${ }^{78}$ die man nicht zu

${ }^{72}$ Wie 'Regb/1/510a stellen auch drei der vier übrigen Bare die Auftrittsrolle des Betroffenen an ihren Anfang. Im Dreierbar ${ }^{~}$ Regb/1/104a verzichtet nur Str. 3, die sich auf den allgemeinen Frauenpreis beschränkt, auf die Auftrittsrolle. Im Siebenerbar ${ }^{1} \mathrm{Regb} / 1 / 553$ wechselt das Lied ebenfalls erst mit Str. 3 in einen allgemeinen Tadel der falschen Zunge, an den noch vier Erzählstrophen anschließen. Im Siebenerbar ${ }^{1}$ Regb/2/31a sind Str. 2, 5 und 7 auszunehmen. Nur im Dreierbar ${ }^{~}$ Regb/1/566a, dessen Lobstrophen 1 und 3 die einschlägige Ich-Rolle vermissen lassen, liefert erst die zweite sie nach.

${ }^{73}$ Nämlich in ${ }^{1} \operatorname{Regb} / 1 / 101,544,554,562,572,573,{ }^{~} \operatorname{Regb} / 2 / 33 a,{ }^{1} \operatorname{Regb} / 3 / 6$ und ${ }^{\prime} \mathrm{Regb} / 4 / 509$.

${ }^{74}$ Vgl. neben STACKMANN zu Mügeln [s.o. Anm. 67] die Belege aus der Spruchdichtung des 13. Jahrhunderts bei EGIDI [Anm. 2], S. 403 Anm. 1187 (dort explizit aus dem Untersuchungskorpus ausgeklammert).

${ }^{75} \mathrm{Zu}$ beiden Liedern ausführlich SCHRÖDER [Anm. 2], S. 191-200. SCHRÖDER weist dort die Vorauer Strophen dem Tonerfinder Regenbogen zu - stillschweigend zustimmend KORNRUMPF [Anm. 2], S. 333 - und erwägt Echtheit immerhin noch für die ersten beiden des >Möserschen Fragments

${ }^{76}$ Vgl. StackmanN/Bertau [Anm. 4], Bd. 1, S. 14lf.

${ }^{77}$ Für ${ }^{1}$ Regb/1/510a erwog BARTSCH [Anm. 17], S. 176 gar Verfasserschaft Regenbogens.

${ }^{78}$ Für ${ }^{1}$ Regb/1/104a, Str. 3 stellt SCHRÖDER [Anm. 2], S. 199f. noch viele weitere Frauenlob-Anklänge zusammen. 
weit von ihren Vorbildern entfernen und erst in die Spätzeit meisterlicher Liedkunst setzen sollte.

Auf der anderen Seite wird die Sängerrolle des Liebenden noch bis in Lieder der Sammlung Eghenvelders $\left({ }^{1} \operatorname{Regb} / 1 / 562\right)$ und gar des Buchdrucks hinein eingenommen ( ${ }^{1} \mathrm{Regb} / 1 / 572 \mathrm{f}$.). Hier reicht die Sangspruchtradition in Tradierungskontexte hinein, die man gemeinhin eher mit dem Liederbuchlied des 15 . und 16. Jahrhunderts verbindet. Eine entsprechende Binnendifferenzierung der Textreihe selbst gelingt am ehesten über die verschiedenen Darstellungsstrategien, mit denen die Sänger ihren Auftritt als Minnebetroffener zu authentisieren suchen:

1. Das Ich tritt als Visionär auf, das seinen Zuhörern die eigene Imagination der Geliebten vor Augen stellt. Die deutlichste Ausprägung bieten die zwei Vorauer Strophen des Tonerfinders selbst: Wer edel hoech geteurte staine sechen wil, der froge mich, dem zaige ich deu im chuerzem zil, drei edel staine, du ich lieb in herzen hil. [...] Groez fraude gebent die hoech geteurten staine, got selber hot se in also hochez golt gelait. ich main dazselbe zartte weib, daz seu do trait ( ${ }^{1} \mathrm{Regb} / 1 / 101$, Str. 1, v. 1-3 und v. 9-11). Unvermittelter stellt in der Strophengruppe des >Möserschen Fragments $<$ der Sänger das geschaute Bild seinem Publikum vor: Eyn mundel rot myr lachte durch mynes hertzen grunt. des ist nicht lank, wol myr, wol myr der leben stunt, das ich den tsuckersuten robynroten munt by lilienwitzen wenghelyn sach, wol mich der oughen blicke! ( ${ }^{1}$ Regb/1/104a, Str. 1, v. 1-4). ${ }^{79}$ Hier ist jetzt darauf verzichtet, die textinterne Vortragssituation (durch eine rhetorische Frage an das Publikum: wer ... sechen wil, der froge mich) als Modellsituation für den idealen Ablauf der textexternen Kommunika-

\footnotetext{
${ }^{79} \mathrm{Vgl}$. für den Vorstellungsbereich des (An-)sehens/(An-)schauens/Scheinens/Strahlens auch Str. 1, v. 7, Str. 2, v. 3, 5f., 12, Str. 3, v. 2, 3, 4, 5, 10, 11. Sowohl bei ${ }^{1} \mathrm{Regb} / 1 / 101$ als auch bei ${ }^{1} \mathrm{Regb} / 1 / 104 \mathrm{a}$ steht zweifellos der markante Beginn des Marienleichs Frauenlobs im Hintergrund: Ei ich sach in dem trone ein vrouwen, die was swanger. die trug ein wunderkrone vor miner ougen anger. Sie wolte wesen enbunden, sust gie die allerbeste, zwelf steine ich zu den stunden kos in der krone veste (GA I,1), der schon in Manesse-C eine Nachtragshand zu einer zusätzlichen kleinen Federzeichnung anregte, die er Bl. $399^{\text {va }}$ neben den Textbeginn des Leichs setzte. Sie zeigt den Visionär - eine männliche Figur, die auf seine Augen verweist und oberhalb von ihm die Gottesmutter mit dem Christuskind im Arm und der mit Steinen besetzten Krone. Vgl. dazu jetzt auch die Einleitung und den Stellenkommentar in: Deutsche Lyrik des späten Mittelalters. Hg. von BURGHART WACHINGER. Frankfurt a.M. 2006 (Bibliothek des Mittelalters 22), S. 823-827, sowie STACKMANN/BERTAU [Anm. 4], Bd. 2, S. 613f. (jeweils mit weiterer Literatur, aber hier wie dort ohne Erwähnung der Federzeichnung).
} 
tion präsent zu halten. Daß das Ich nicht realiter Gesehenes, sondern vor seinem inneren Auge stehendes beschreibt, wird als selbstverständlich vom Publikum gewußt vorausgesetzt. ${ }^{80}$

2. Das visionär geschaute Bild wird szenisch verlebendigt, indem das Ich in ein Gespräch mit der imaginierten Dame eintritt. Das wird ebenfalls bereits in den frühen Vorauer Strophen versucht: Ich wond, der meinen selden tag der wold auf gan, do ich in sach, den munt, so zertleich vor mier stan, recht als er sprechen wold zu mier: >nu frau dich, man, mein suezichait ...< [Textabbruch] $\left({ }^{1}\right.$ Regb/1/101, Str. 2, v. 5-8). In ein Gespräch mit der Geliebten, die dadurch als unmittelbar anwesendes Gegenüber vorgestellt wird, tritt das Ich auch in ${ }^{1} \mathrm{Regb} / 1 / 544,553,554 \mathrm{a}, 562,566,{ }^{1} \mathrm{Regb} / 2 / 31 \mathrm{a}$ und 33a ein. ${ }^{81}$ Während der Konstruktcharakter dieser szenischen Verlebendigungsversuche in ${ }^{1} \mathrm{Regb} / 1 / 101$ aber durch eine konjunktivische Ankündigung der Rede in v. 7 der zweiten Strophe noch bewußt gehalten wird (recht als ...), bedarf es wiederum in den anderen Beispielen keiner textuellen Signale mehr, die den fiktiven Charakter des Gesprächs mit jemandem, der in der Situation des Liedvortrags gar nicht anwesend ist, markieren.

3. Authentisierung wird weiterhin oft durch die Ausgestaltung des Lied selbst als Gruß an die Geliebte erreicht. Im Vortrag des Liedes selbst vollzieht sich dann die Minnebeziehung insofern, als es selbst als Teil der Kommunikation zwischen den Minnenden fungiert. Got grü $\beta$ min liep in zuckersußer selikeit, got grü $\beta$ myn lieb mit rotten rosen wolbecleit, got gruß myn liep, myn hercz ein edels röschen treit. sie ist die hochste freude myn, in truwen ich sie meyne. got grüß dich, liep, ich lob dich fur dez meyen blut beginnt ${ }^{1} \mathrm{Regb} / 1 / 544$, Got grüss dich, lieb, gott grüss dich, zart, got grüss dich, fin. gott grüss dich, herczen lieber schóne büle min ${ }^{1} \operatorname{Regb} / 1 / 553$, und Got grü $\beta$ mein lieb, got grüß dich traut, got grü $\beta$ dich zart die Mittelstrophe in ${ }^{1} \mathrm{Regb} / 1 / 572$.

${ }^{80}$ Die Eingangsstrophe von ${ }^{1}$ Regb/1/510a (mit sechs folgenden objektiven Lobstrophen) läßt sich bereits als Variante des Visionsschemas lesen: Nicht das Ich sieht, sondern wünscht sich, daß es von dem wîplich[] bilde ûz herzen grunt selbst gesehen würde (v. 1).

${ }^{81}$ Wiederum ist sicherlich auch der Marienleich Frauenlobs mitzuhören, in dem das Ich die Gottesmutter in I,8 v. 24f. unmittelbar anspricht und zu eigener Rede auffordert (vil schöne ob allen vrouwen, sprich: [>]der schönen liebe ein muter ich [...]<). Von da an bestimmt dann die >Selbstrühmung « Marias den Leich. Daß sie Maria vom Ich nur in den Mund gelegt wird, das selbst übergeordnete Sprecherinstanz bleibt, wird im weiteren Fortgang des Textes dann nicht mehr durch entsprechende Sprachmittel markiert. Folglich muß sich bei voranschreitender Textrezeption - sei es hörend, sei es lesend - zunehmend die Vorstellung einer Eigenrede Marias herausbilden. Prinzipiell aber verdeckt die Bezeichnung als >Selbstrühmung « den in v. 24 eigens herausgestellten Konstruktcharakter der Rede Mariens. 
4. Ihre größte Wirksamkeit konnten die skizzierten Authentisierungsstrategien unmittelbar im Liedvortrag vor Anwesenden entfalten durch Auftritt des Sängers als Visionär, szenische Vergegenwärtigung des Gesprächsgegenübers, begleitende Grußgesten. Dort machen sie freilich die Rede des Ich unweigerlich immer auch als inszenierte kenntlich. Das leistet die textexterne Vortragssituation: Schon im unmittelbar vorangehenden oder folgenden Lied hat das Ich vielleicht schon gar keine >Visionen< mehr, und sein unmittelbares Gesprächsgegenüber, die Dame, ist unter den Zuhörern ebensowenig selbstverständlich anwesend wie das Objekt seiner Grüße. Es bleiben freilich, wie in allen Aufführungskünsten, gelegenheitsgebundene spielerische Referentialisierungen prinzipiell immer möglich. Einige Lieder verzichten nun allerdings weithin oder sogar ganz auf derartige Authentisierungsversuche.$^{82} \mathrm{DaB}$ in ihnen ein - jetzt nurmehr monologisierendes - Ich sich als Liebendes lediglich inszeniert, ist damit allein noch in der einschlägigen literarischen Tradition geschulten Zuhörern durchschaubar. Nur ihnen mögen bereits leise Anklänge an die skizzierten Authentisierungsstrategien nicht einfach als gängige >Motive< eines konventionellen Repertoires erscheinen, sondern als immerhin noch schwache Fingerzeige darauf, daß hier kein Ich authentisch innere Befindlichkeit aussagt. ${ }^{83}$ Durch das Zurücktreten der Authentisierungsund Inszenierungssignale ist es freilich zugleich dem Publikum solcher Lieder leichter gemacht, selbst als ihr Reproduzent aufzutreten, d.h.

\footnotetext{
${ }^{82}$ Hierher zu stellen sind ${ }^{~} \operatorname{Regb} / 1 / 573,{ }^{~} \mathrm{Regb} / 3 / 6$ und ${ }^{\prime} \mathrm{Regb} / 4 / 509$. Wenn man von der Grußstrophe 2 absieht, gehört auch das allein aus einem Druck von 1525 bekannte Lied 'Regb/1/572 hierher. 'Regb/1/573 ist allein in einem Druck von 1529 überliefert. 'Regb/3/6 ist allein aus $\mathrm{k}$ bekannt und überhaupt das einzige Lied im Untersuchungsbestand in diesem Ton. Es mag sich um ein singuläres, spätes $>$ Liebeslied $<$-Experiment ohne Anbindung zur Thementradition des 14. Jahrhunderts handeln. Auch 'Regb/4/509 ist allein aus $\mathrm{k}$ bekannt.

${ }^{83} \mathrm{Im}$ Motiv des Fensters etwa, in dem in der Eingangsstrophe von 'Regb/1/572 dem Ich seine Geliebte erscheint, wird der Gegensatz von sinnen Opposition von innerlich erschauter Vision und ihrer veräußerlichenden Kundgabe im Liedvortrag abbildet, noch einmal im Innenbereich der dargestellten Welt wiederholt. Und dieses Spiel mit den Grenzverdoppelungen wird hier sogar noch weiter in Richtung auf die Überschreitung von Grenzen fortgesetzt. Das geschieht einmal, indem die Geliebte dem sprechenden Ich statt nur ihre Blicke ganz sreal sogar einen Apfel zugeworfen haben soll (Jch sach mein lieb an aim fenster allaine, die rain, die zart, die lag so ferr von mir hindan, da dacht ich mir in meinem müt ich senender man, das weder künig noch kaijser schóners bild nije gwan, sij warff mir ainen apfel dar, dardurch kam ich in peine, v. 9-13). Zum weiteren wird das textinterne Publikum ironisch aufgefordert, in die wirkliche Welt auszugreifen (nun helfft mir alle bitten hie, das sij mir werd in trewen, v. 8).
} 
singend selbst die Rolle des liebenden Ich einzunehmen. Es sinkt also die Schwelle zu ihrer Instrumentalisierung in gesellig-unterhaltenden Rollenspielen, ${ }^{84}$ in denen dann der Gesamtauftritt des Vortragenden als solches, sein erkennbarer Auftritt nämlich als >Wieder-Sänger<, als >Künstler-Reproduzent< eine ganz andersartige, nämlich generelle Distanz zur Textrolle des Liebenden aufbaut.

Die deutlichen Ausformungen Nr. 1-3 häufen sich eher in den früh bezeugten oder in der Strophenordnung noch wechselnden Liedern, die >flachere Ausformung mit dem monologisierenden Ich begegnet eher in den späten Belegen. Diese Verteilung könnte eine generelle sein. Jedenfalls paßt zu ihr, daß von den Zwischenformen, die die älteren, wenn man so will >klassischen< Inszenierungsformen bereits abwandeln, nirgends ein Weg eindeutig noch weit ins 14. Jahrhundert zurückführt. Denn allein in $\mathrm{k}$ bezeugt ist ${ }^{1} \mathrm{Regb} / 1 / 544$, in dem das Ich nach einer anaphorischen Reihung von Grüßen an die Geliebte (v. 1: Got grüß min liep in zuckersußer selikeit) nun diese in der Mittelstrophe ausdrücklich auffordert, dies Tun nun endlich zu entlohnen (v. 1f.: $G e$ nad mir liep, nu han ich dich gegrüsset schon. genad mir liep, dez soltu mich geniessen lon), was ihm aber in direkter Gegenrede der Geliebten zu Beginn der Schlußstrophe gerade verweigert wird (v. 1: Hat dich der mynnen stral verhauwen, junger man?). Allein die frühe Meisterliederhandschrift b belegt um 1430 das Siebenerbar ${ }^{1}$ Regb/1/553, in dem auf wiederum einleitende anaphorische Grußreihen (v. 1: Got grüss dich, lieb, gott grüss dich, zart, got grüss dich, fin) wiederum die Absage in direkter Gegenrede der Dame folgt - die sich dann aber doch als nicht ernst gemeinte zu erkennen gibt und zu einer Reihe von fünf Erzählstrophen überleitet, die mit einer im bäuerlichen Milieu situierten Beispielerzählung, deren Anbindung etwas gezwungen-unbeholfen anmutet, belegen, daß man die eigenen Wünsche besser vor der welte nit $z u$ brait (Str. 2, v. 11) machen solle. Ebenfalls erst aus b sowie dann zwei Lieddrucken bekannt ist das Siebenerbar ${ }^{1} \mathrm{Regb} / 1 / 554 \mathrm{a}$, das in zwei Strophen einen erfolglosen Dialog des Ich mit der wiederum abweisenden Geliebten vorführt, auf den eine Reihe weiterer Strophen folgt, in denen das Ich sich kontinuierlich weiter in die Absage an die Liebe und die Welt hineinsteigert, um schließlich Gott selbst anzurufen. ${ }^{85}$ In dem Fünferbar ${ }^{1}$ Regb/1/562, das allein Eghenvelders >Lieder-

\footnotetext{
${ }^{84}$ Vgl. zu deren Spielräumen um 1400 ECKHART CONRAD LuTZ: Das Dießenhofener Liederblatt. Ein Zeugnis späthöfischer Kultur. Freiburg/Br. 1994 (Literatur und Geschichte am Oberrhein 3), S. 23-34.

${ }^{85}$ Textausgabe: KARL BARTSCH: Beiträge zur Quellenkunde der altdeutschen Literatur. Straßburg 1886, S. 291-294.
} 
buch < überliefert, muß das Ich im Gespräch mit der Geliebten erst noch alle seine Überredungskünste aufwenden, um diese sich geneigt zu machen. Um mit zwei Beispielen wenigstens punktuell auch über das Regenbogen-Korpus einmal hinauszugreifen: Vor dem Hintergrund solcher bereits differenzierteren Verarbeitungen der traditionellen Authentisierungsformen hat zweifellos um 1400 Suchensinn seine Lieder ver$\mathrm{fa} ß \mathrm{t}$, in denen die Ich-Rolle auf originelle Weise weiter ausgebaut und differenziert wird; ${ }^{86}$ und das eingangs erwähnte, erst in der zweiten Hälfte des 15. Jahrhunderts entstandene Liebeslied des Nürnbergers Folz schließlich verzichtet bezeichnenderweise auf visionär-imaginierende Darstellungselemente, auf den Gruß, auf die breitere Vergegenwärtigung des Gegenübers in direkter Rede. Folz mag Kenntnis von älteren Gepflogenheiten des Sprechens von Frauen und Minne in der Sangspruchtradition gehabt haben, knüpft daran aber nicht aktiv an. Sein Meisterlied Nr. 69 steht wohl dem zeitgenössischen Liebeslied näher. Das wird durch den Verzicht auf den breiteren Lobpreis der Frau als solcher noch unterstrichen, dem ja schon die knapp bemessene Strophenform des nur hier benutzten (und demnach vermutlich für das vorliegende Lied geschaffenen) Tons kaum mehr Raum geben konnte. ${ }^{87}$ Damit aber entfällt bei Folz zusätzlich der das subjektive meisterliche Rollenlied von der Minne noch weithin prägende Bezug auf ein Allgemeines.

${ }^{86}$ Vgl. MARGRETH EGIDI: Dissoziation und Status der Ich-Rolle in den Liedern Suchensinns. ZfdPh 119 (2000), Sonderheft »Neue Forschungen zur mittelhochdeutschen Sangspruchdichtung«, S. 237-251. Zu Autor, Werk und Überlieferung insgesamt: FrIEDER SChANZE: Suchensinn. In: ${ }^{2}$ VL, Bd. 9, Sp. 478-481; SCHANZE [Anm. 3], Bd. 1, S. 137-145, Bd. 2, S. 26-28; RSM 'Suchens/1-24 (mit Nachweis der Textausgaben; für einen Nachtrag zur Überlieferung s. ZfdPh 119 [2000] 427-433). Die textinterne Ich-Rolle mit dem biografischen Namen des Textdichters zu belegen, hat etwas später bei Muskatblut System. Da schon bei dessen "Liedern mit Dialogszenen das Vorbild Suchensinns nicht zu übersehen [....] « ist (SCHANZE [Anm. 3], Bd. 1, S. 175, in der Überschau über Lieder Muskatbluts mit Minne- und Frauenthematik), lassen sich hier die Linien vom alten Spiel der späten Sangspruchdichter/frühen Meisterlieddichter mit der Rolle des Minne-Betroffenen zumindest im Bereich der Berufsmeister bis weit ins 15. Jahrhundert hinein verfolgen.

${ }^{87}$ Das ist im Prinzip auch für das allein aus $\mathrm{k}$ bekannte Liebeslied in der lediglich siebenversigen, relativ schlichten Grundweise Regenbogens festzuhalten, die von daher - wenn die Überlieferung nicht täuscht - kaum zufällig nicht gerade häufig für dieses Thema herangezogen wurde $\left({ }^{1} \mathrm{Regb} / 3 / 6\right)$. Aufgefangen wird der Verzicht auf den expliziten Preis dort aber immerhin noch durch die nahezu durchgängige Exposition des Ich als vom Anblick der Geliebten erfreutes Ich, das damit exemplarisch für die prinzipielle Preiswürdigkeit und das Freude spendende Vermögen der Frau einstehen kann. Bei Folz hingegen tritt das Ich als sehnendes und werbendes auf. 


\section{Kulmination:}

\section{Der Wettstreit um den Vorzug von Frau oder Mann}

Da sie speziell an den legendären Dichterstreit zwischen Frauenlob und Regenbogen anknüpfen, scheinen der $>$ Krieg von Würzburg ${ }^{88}$ mit seinem fiktiven Sängerwettkampf zwischen Frauenlob und Regenbogen um den Vorzug von Mann oder Frau und das erst aus der >Wiltener Handschrift< w und einem Würzburger Druck um 1500 überlieferte dreistrophige Lob des Mannes ${ }^{89}$ zunächst nur bedingt in über die Verhältnisse in Regenbogen-Tönen hinaus verallgemeinerbare Zusammenhänge zu führen. Insbesondere der >Krieg von Würzburg ‘ aber führt noch einmal zentrale Elemente der Poetik der späten Sangspruchdichtung zusammen. Schon der Eingangsvers Erst tugende rîch der gerne horet guoten sanc klingt programmatisch, richtet er doch die Wahrnehmung der Zuhörer an erster Stelle auf den guoten sanc als solchen aus.

Die Frage, was aber dann der Sänger denn eigentlich zu sagen hat, tritt hinter seinen Auftritt als solchen zurück. Ob nun Frauen oder Männern der Vorzug zu geben sei, wird daher in dem ganzen Streit letztlich nicht mehr entschieden. Zumindest die - wohl ältere - k-Fassung beschließt den Streit mit einer vermittelnden Position, die beide Parteien zu ihrem Recht kommen läßt: dar umbe zimt uns kristen wol daz wir sie êren beide (Str. 23, v. 8). ${ }^{90}$

${ }^{88}{ }^{1} \mathrm{Regb} / 1 / 512 \mathrm{a}$ (k: 23 Strophen) und 'Reb/1/512b (w: neun Strophen). Text: BARTSCH [Anm. 17] Nr. 61 (nach k). Vgl. neben den RSM-Angaben zur Forschung jetzt noch BALDZUHN [Anm. 2], S. 28f., und EGIDI [Anm. 2], S. 208 Anm. 730 [Hinweis auf die Verwendung des mariologischen Arguments für den Vorzug der Frau in den Strophen mit der Frauenlob-Rolle] und S. 410 [unter »Frauenpreis«]), sowie zur zeitlichen Einordnung neben BARTSCH (S. 176 »auch wohl aus der ersten hälfte des 14 jahrhunderts $«$ ) BURGHART WACHINGER: Sängerkrieg. Untersuchungen zur Spruchdichtung des 13. Jahrhunderts. München 1973 (MTU 42), S. 288: „Es wäre wohl denkbar, daß der Verfasser in die gleiche Würzburger Tradition eines Interesses an den älteren meistern gehört, die uns durch Michael de Leone und Lupold Hornburg bekannt ist.«

${ }^{89}$ 'Regb/1/565ab. Der Text der ersten Strophe bei IGNAZ V. ZINGERLE: Bericht über die Wiltener Meistersängerhandschrift. WSB 37 (1861) 331-407, hier S. 351f. Zur zweiten und dritten Strophe s.u. Anhang 2.

${ }^{90}$ Auch darin setzt sich die w-Fassung, wie schon WACHINGER ([Anm. 88], S. 288) vermutet hat, als spätere ab, denn in ihr wird schlieBlich doch für den Mann als den vorzüglicheren der beiden votiert. Derselben späteren Schicht wird das ebenso einseitiger ausgerichtete sLob des Mannes zugehören, das ebenfalls u.a. auch von w überliefert wird. Das Interesse an Vereindeutigung als solches zielt indes noch nicht zwangsläufig auf einen prinzipiell andersartigen Publikumskreis (wie er oben für die Warnung vor Frauen und Würfelspiel in 'Regb/1/3/15 vermutet wurde), der nicht mehr selbstverständlich Frauen wie Männer gleichermaßen umfaßt. Das textinterne Publi- 
Da das Selbstverständnis der höfischen Gesellschaft sich gewichtig über ihre kunst-Kompetenz bestimmt, werden wiederum als bekannt vorausgesetzte höfische Erzählstoffe als Folie aufgerufen: bistuz her Gâwîn, sô bin ichz her Parzifâl. lâ sehen wer under uns ersinge hie den Grâl, und wer mit kunst behalte hie, daz in die merker prîsen, schlägt die Regenbogen-Figur vor (Str. 4, v. 11-13).

Allerdings wird die allgemeine literarische Kompetenz nun im Aufruf der - vielleicht historischen - Auseinandersetzungen zwischen zwei prominenten Sangspruchdichtern noch enger auf die Geschichte speziell der Gattung >Sangspruch ‘ geführt. Mit der Inszenierung des Dichterstreits wird entsprechend auch eine gattungsspezifische Rezeptionskompetenz als grundsätzlich vorhanden unterstellt, die gleichsam als kognitive Eintrittskarte zu einer anstehenden Theateraufführung fungiert und - wie in den subjektiven Frauenpreisstrophen - die einfache biografische Referenzialisierung des Text-Ich auf den oder die (sofern man eine szenische Realisierung des Wettstreits von gleich zwei Sängern in Betracht zieht) Sänger verhindert. ${ }^{91}$

Mit der Wahl der Vortragsform >Sängerwettstreit< liegt es für den >Krieg von Würzburg ‘ dann noch näher als in anderen Liedern, das Kampfgeschehen des Turniers als Hintergrundbild in die Aktionen des oder der auftretenden Sänger einzuspielen - zum Beispiel in Str. 6:

Ich Frouwenlop, durch frouwen êre kom ich her.

swer singen wil, ich füer ein schilt und ouch ein sper.

durch frouwen êre var ich in dem lande entwer:

swâ man ir wirde erstrîten sol, dâ bin ich ie der eine.

Durch frouwen êre halt ich hie ûf diser ban,

durch frouwen êre lege ich mîne wâfen an,

durch frouwen êre hân ich ie daz beste getân,

durch frouwen êr bind ich den helm: in triuwen ich sie meine.

Als Konsequenz der gesteigerten literarischen Kompetenz und der Ausrichtung der Wahrnehmung auf den Vortrag als solchen erscheint die Stärkung der Rolle des internen Publikums, das statt nur als Zuschauer oder Zuhörer angesprochen zu werden, mehrfach dezidiert zu eigenem kunst-Urteil aufgefordert wird. ${ }^{92}$ Seine Apostrophe als merker und das

kum im >Lob des Mannes< schließt erstere durchaus noch mit ein; vgl. Str. 2, v. 13 das laut euch rainen frauen nit verschmachenn und Str. 3, v. $9 \mathrm{Jr}$ werden frawen [...].

${ }^{91}$ In Str. 3, v. 3f. tritt die Frauenlob-Figur in eben der Rolle des Minnebetroffenen auf: Durch mînes liebes willen wil ich heben an, durch mînes liebes willen wil ich frô bestân, durch mînes liebes willn, wer nimt sich singens an?

${ }^{92} \mathrm{Vgl}$. Str. 3, v. 7f. ir merker, merkent alle glich an diser schar, ich halte tretzeclichen hie ûf mînem ros ze brangen; Str. 4, v. 2-4 ir merker, merkent, sanges hân ich mich 
Motiv des ausgehängten Kränzleins (Str. 3, v. 4: ein krenzel ûz gehangen) weisen auf das Geschehen im Gemerk der Meistersinger seit dem ausgehenden 15. Jahrhundert voraus. Dort werden eben solche StreitInszenierungen dann aber nur noch einmal nachinszeniert. ${ }^{93}$

Nur für drei Meisterlieder lassen sich im engeren Rahmen des RegenbogenKorpus keine Ausgangspunkte mehr fest machen, die mit Sicherheit noch ins 14. Jahrhundert zurückführen. Das hebt sie von den in den Abschnitten 2 bis 6 zusammengestellten Texten ab. Hier werden zukünftig weitere Vergleichsreihen abzusichern und zu differenzieren haben, was einstweilen nur die handschriftliche Überlieferung und die jeweilige Ausgestaltung des Themas Minne/Frauen nahelegen: $d a \beta$ es sich bei diesen drei Liedern sehr wahrscheinlich erst um spätere Produkte des 15. Jahrhunderts handelt.

Das Dreierbar ${ }^{1}$ Regb/1/563 in der Briefweise ('Verprügelung des üblen Weibes $<$ ) ergeht sich breit im Rat des Ich an einen ungenannten Hilfesuchenden, seine Frau nur über den ganzen Tag hinweg regelmäßig zu verprügeln, um sie gefügig zu machen. Frühester Textzeuge ist das >Liederbuch des Jacob Käbitz‘ aus dem zweiten Viertel des 15. Jahrhunderts. BOLTE charakterisiert das Bar als eine "grobe, weiberfeindliche Lehre des 15 . Jahrhunderts « ${ }^{94}$

In den sieben Strophen von ${ }^{1}$ Regb/1/567, das zuerst die um 1500 in Augsburg geschriebene Meisterliederhandschrift $\mathrm{h}$ überliefert, belauscht das Ich sieben Frauen auf einem plan, die bis auf eine über die Vorzüge und Nachteile ihrer Ehemänner schwatzen. ${ }^{95}$ Allein von der letzten, die ihre Augen zuhtigcliche nider schlägt (Str. 7, v. 1) und aus deren Mund die Didaxe spricht, werden sie angehalten, doch in diesen Fragen verschwiegener zu sein, da es den frawen zimpt nit wol, die also vile losen. Das wäre ihrem eigenen Ansehen zuträglicher (Str. 7, v. 9: dencken an eur eren; v. 12: so mugen ir vil breis beiagen). Hervorgehoben zu werden verdient die Übernahme der Spaziergangseinleitung aus den Minnereden. ${ }^{96}$ Denn man hat für die Entstehung des mehrstrophigen

erwegen. mich heischet ûz gar üppeclîch ein stolzer degen. er hât verbunden sînen helm und neigt sîn sper mit schalle; Str. 4, v. 12f. lâ sehen wer under uns ersinge hie den Grâl, und wer mit kunst behalte hie, daz in die merker prîsen.

${ }^{93}$ Dazu ausführlicher BALDZUHN [Anm. 2], S. 486-494.

${ }^{94}$ Text: JOHANNES BOLTE: Zum deutschen Volksliede. 31. Vom üblen Weibe. Zeitschrift für Volkskunde 18 (1908) 76f. (das Zitat S. 77). Vgl. ferner EGIDI [Anm. 2], S. 414, wo das Lied unter den Beispielen für »Ehespruchstrophen ohne Berührung zum Liebesdiskurs « aufgeführt ist. Ein entsprechender Traditionshintergrund weist allerdings durchaus noch ins 13. Jahrhundert zurück. Siehe dazu die Hinweise bei HeLmUT LOMNITZER: Geliebte und Ehefrau im deutschen Lied des Mittelalters. In: Liebe, Ehe, Ehebruch in der Literatur des Mittelalters. Hg. von XENJA vON ERTZDORFF und MARIANNE WYNN. Gießen 1984 (Beiträge zur deutschen Philologie 58), S. 111-124, hier S. 114.

${ }^{95}$ Text: Schulz [Anm. 2], S. 41-43. Vgl. den kurzen Kommentar dazu S. 125 sowie S. $184-188$.

${ }^{96} \mathrm{Vgl}$. INGEBORG GLIER: Artes amandi. Untersuchung zu Geschichte, Überlieferung und Typologie der deutschen Minnereden. München 171 (MTU 34), S. 394-399. 
Meisterlieds im 14. Jahrhundert einen Einfluß der Redendichter erwogen, deren im Vergleich zum Sangspruch ja wesentlich längere Gedichte hier wirksam geworden sein könnten. ${ }^{97}$ Es bleibt daher einstweilen zum mindesten bemerkenswert, daß sich Berührungen zu den Minnereden in den Regenbogen-Liedern von Minne und Frauen allein in ${ }^{1}$ Regb/1/567 und erst so spät finden.

${ }^{1} \mathrm{Regb} / 1 / 568$ bietet eine fünfstrophige Klage des Ehemannes über seine falsche Verheiratung.$^{98}$ Es handelt sich um das einzige Beispiel im ganzen Bestand für eine eindeutige Ausgestaltung der Beziehung zwischen Mann und Frau im rechtlich verbindlichen, dauerhaften Rahmen der Ehe. Bezeugt ist es erst aus der Hans-Sachs-Handschrift q aus dem 16. Jahrhundert. Die Institution der Ehe als bedeutsames Element der Lebenswirklichkeit des neuen Trägers der Sangspruchtradition im 15. Jahrhundert, des Handwerkers, nimmt demnach auf die literarischen Ausgestaltungen der Beziehung zwischen Mann und Frau erst spät durchgreifenden Einfluß. Die in den Texten entworfenen Geschlechterbeziehungen erscheinen über weite Strecken stärker von der innerliterarischen Tradition der Gattung bestimmt als von der außerliterarischen sozialen Realität. ${ }^{99}$

\section{Literarisierung in der $>$ Kunst der Minne $<$}

Wieweit sich die Verhältnisse im Regenbogen-Korpus verallgemeinern lassen, ist einstweilen kaum zu sagen. Anstatt Verbindungslinien in weitere Textbestände des meisterlichen Liedes im 14. und 15. Jahrhundert zu ziehen, die das bis hierher Festgestellte weiter abstützen, will es mir beim gegenwärtigen Forschungsstand sinnvoller erscheinen, die skizzierten Befunde zu Leitthesen einer weiteren Erschließung des späten Sangspruchs und des frühen meisterlichen Liedes zu verallgemeinern.

1. Höfische Minne ist und bleibt ein Thema in der späten Sangspruchdichtung des 14. Jahrhunderts um und nach Frauenlob und Heinrich von Mügeln, und dies gerade auch unter den uns nicht mehr mit Namen greifbaren Nachsängern, die sich für ihre Texte fremder Töne bedienten. Das Singen von der Minne unterliegt freilich im 14. Jahrhundert signifikanten Veränderungen. Die Thematisierung des Minneprozesses als solchen, dem das Interesse bereits der älteren Spruchdichter zumeist nur am Rande galt, tritt noch weiter in den Hintergrund.

\footnotetext{
${ }^{97}$ BRUNNER [Anm. 8], S. 402f.

${ }^{98}$ Text: SCHULZ [Anm. 2], S.94f. mit kurzem Kommentar dazu S. 139 sowie S. 198-201. Vgl. auch EGIDI [Anm. 2], S. 414 (unter den Beispielen für »Ehespruchstrophen ohne Berührung zum Liebesdiskurs «).

${ }^{99}$ Vgl. zum Verhältnis von Minne und Ehe in der Spruchdichtung LOMNITZER [Anm. 94], besonders S. 113f. und S. 119f.; EGIDI [Anm. 2], S. 83 mit Anm. 379; STACKMANN [Anm. 2], S. 153f. (zu Frauenlob).
} 
Hingegen ist die mehr oder minder unvermittelt an das weibliche Geschlecht gerichtete Belehrung in Form vergleichsweise unvermittelter Ermahnung durch den Spruchdichter, der dann in der Rolle des Sprachrohrs allgemeiner gesellschaftlicher Erwartungen an das Verhalten der Frau auftritt, zwar noch vergleichsweise häufiger anzutreffen, verliert aber im Verhältnis zu anderen Ausformungen an Gewicht. Unter diesen tritt auffallend breit nun der Preis der Frau (der implizit selbstverständlich ebenfalls didaktisch funktionieren kann, so daß an entsprechende Strophen explizite Belehrungsstrophen von Fall zu Fall immer wieder auch anknüpfen) in subjektivierter Form hervor: Das Ich nimmt die Rolle einer selbst von der Minne betroffenen Person ein.

2. Für das gewichtige Hervortreten des subjektiven Frauenpreises läßt sich kein einzelner Anstoß allein namhaft machen. Die Ausformung ist schon der Gattung selbst im Prinzip nicht neu, wird in ihr nur zu neuem Gewicht gebracht. In der Nachbargattung des Minnesangs ist die in den Sangsprüchen und Meisterliedern zentrale, gleich mehrfach anzutreffende Strategie zur Authentisierung der subjektiven Minneerfahrung, das sprechende Ich als Visionär auftreten zu lassen und die Minnedame sich und seinem Publikum als inneres Bild vor Augen zu stellen, schon Heinrich von Morungen geläufig. Zudem wird aus dem Bereich der Leichdichtung ein wichtiger Anstoß vom wirkungsmächtigsten Leich der Zeit überhaupt, von Frauenlobs Marienleich, ausgegangen sein, der, wo als Hintergrund präsent, immer auch Vorstellungen von der Gottesmutter Maria als Idealbild der Frau schlechthin in die jeweiligen Strophen und Lieder einspielt. Erklärungsversuche müssen also stets das gesamte System der lyrischen Gattungen berücksichtigen - und überdies nicht-lyrische Gattungen wie die Minnerede, die speziell man ja mit der neuen Mehrstrophigkeit im 14. Jahrhundert in Verbindung gebracht hat. Zur Minnerede lassen sich einstweilen allerdings bemerkenswert wenig wirklich eindeutige Verbindungen erkennen. Ihre Bedeutung für die Umformungsvorgänge in der späthöfischen meisterlichen Lieddichtung des 14. Jahrhunderts wird wohl überschätzt.

3. Das Hervortreten des Text-Ich und seine Ausgestaltung als selbst von Minne betroffener Figur authentisiert den Frauenpreis, indem es ihn an eigene Erfahrung des Ich anbindet, und personalisiert ihn zugleich. ${ }^{100}$ Der Auftritte des Sängers in der Rolle des eher unpersönli-

${ }^{100}$ Es setzt sich damit in gewisser Weise ein Prozeß fort, in dessen Verlauf ein Ich innerhalb der Gattungsgeschichte des Sangspruchs im 12. und 13. Jahrhundert ohnehin zunehmend profilierter auftritt; vgl. GRUBMÜLLER [Anm. 16]. 
chen Mahners, der ein allgemein geteiltes Wissen von der Preiswürdigkeit der Frau voraussetzt, verliert an Attraktivität - sicher nicht überall, aber wohl in avancierteren Publikumskreisen. Speziell vor diesen zunächst im 14. Jahrhundert gewiß noch überwiegend adeligen $-\mathrm{Zu}-$ hörern vermochten sich die späten Sangspruchdichter und frühen Meisterlieddichter mit subjektiven Frauenpreisstrophen dagegen in einer weitergehenden Weise als bisher als Mitglieder der höfischen Gesellschaft zu profilieren. Sie rücken nämlich mit ihren in der Rollenkonstruktion dem Minnesang angenäherten Auftritten in die Position desjenigen, der selbst ebenfalls höfisch zu lieben vermag.

4. Die Annäherung des Fahrenden an den Minnesänger vollzieht sich allerdings zugleich - das ist immer mit zu sehen - in einem im 14 . Jahrhundert sich folgenreich wandelnden Rezeptionsrahmen. In ihm wird der Gattung ein nunmehr ausgeprägterer Kunstcharakter zugebilligt, werden Textvorträge deutlicher als dezidiert literarische Veranstaltungen wahrgenommen. Eine generelle Literarisierung der Gattung und ihres Publikums in einer Spätphase der Sangspruchdichtung/Frühphase meisterlicher Lieddichtung zeigen bereits die neue Mehrstrophigkeit als solche und die Ausweitung der Fremdtonverwendung an. Erstere setzt stabilisierte, in höherem Maße berechenbare Rezeptionskontexte der Gattung voraus. ${ }^{101}$ Letztere kann offenbar mit nunmehr breiteren Kenntnissen auf der Publikumsseite in Fragen der Tonautorschaft rechnen. ${ }^{102}$ Ablesen läßt sich diese Literarisierung weiterhin an: - dem Erfolg des Typs Erzähllied, das sich durchaus nicht schlicht darauf beschränkt, den Freiraum der neuen Mehrstrophigkeit zu nutzen, sondern zumindest dort, wo es von Frauen und Minne handelt, direktere Belehrungen von Mann und Frau hinter die unterhaltsame Vorführung von Spielarten des Umgangs der Geschlechter miteinander zurücktreten läßt. Solche Lieder aber stiften höfische Konsensgemeinschaft nicht primär über Zustimmung, Ablehnung oder Anstoß zur Diskussion von ihnen ausgesagter Inhalte, sondern zuvor und grundlegender schon über das von ihnen implizit vorausgesetzte und dann bestätigte Einverständnis eines vom Textverfasser bereits als kunstverständig erwarteten (und sich selbst auch so verstehenden) Publikums, einem unterhaltsamen Vortrag entsprechenden Freiraum zubilligen zu wollen;

${ }^{101}$ BALDZUHN [Anm. 2], S. 55-68.

${ }^{102}$ Die wechselnden Praktiken innerhalb der Sangspruchtradition skizzieren grundlegend: GISELA KorNRUMPF / BURGHART WACHINGER: Alment. Formentlehnung und Tönegebrauch in der mittelhochdeutschen Spruchdichtung. In: Deutsche Literatur im Mittelalter. Kontakte und Perspektiven. Hugo Kuhn zum Gedenken. Hg. von CHRISTOPH CORMEAU. Stuttgart 1979, S. 356-411. 
- der Inszenierung des eigenen Liedvortrags als Wettkampf, die den Frauenpreis des Sängers als verteidigenswerten authentisiert, publikumsseitig aber auch gesteigerte Verstehensleistungen einfordert: Rollenspiele wollen als solche erkannt, gattungsgebundene $>$ Vorgeschichten (Frauenlob vs. Regenbogen) müssen mitgehört und der Liedvortrag will als Schauplatz höfisch-ritterlichen Handelns in actu goutiert werden;

- den häufigen Auftritten von Exempelfiguren aus der klassisch-höfischen Erzähldichtung, deren Kenntnis unter der Zuhörerschaft vorausgesetzt wird und die als Medium eines gesteigert literaten Selbstverständnisses aufgerufen wird. ${ }^{103}$

5. Der Auftritt des Sängers in derart literarisierten Rezeptionskontexten erscheint bisweilen bereits wie von Theatervorhängen gerahmt. Funktional übernimmt solche Rahmung das beträchtlich angestiegene Vorwissen auf Seiten des Publikums, das der kunst des Sängers einen besonderen Freiraum gewährt. Daher ist, sofern man nur bereit ist, in die vornehmlich um den hochmittelalterlichen Minnesang kreisende Diskussion um die Legitimität und Reichweite des Fiktionalitäts- und des Rollenbegriffs für das Verständnis mittelalterlicher volkssprachiger Lieddichtung entschiedener auch einmal die spätmittelalterlichen Verhältnisse einzubeziehen, von der Literarisierung des späten Sangspruchs im 14. Jahrhundert her für diese Diskussion weiterreichender Aufschluß zu erwarten. ${ }^{104}$ Gerade das Spiel mit Eigennamen und der Autorrolle sind jedenfalls bei späteren Berufsmeistern wie Suchensinn und Muskatblut ohne Rücksicht auf die Vorleistungen der frühen Meisterlieddichtung nicht zureichend zu verstehen. Doch auch zum Liederbuchlied des 15. Jahrhunderts bestehen aufschlußreiche Verbindungen. Texttypologisch betrachtet nämlich ist der Schritt zumal vom subjektiven Frauenpreis in einem Sangspruchton zum Liederbuchlied mitunter minimal. Schon der einfache Verzicht des Textdichters darauf, die Imagination der geschauten Geliebten als solche sprachlich durchsichtig zu halten - statt »Seht, ich habe selbst und stelle auch euch hier vor Augen sie, die $[\ldots]$ « nur ein »Ich habe vor Augen sie, die [...] überspielt Gattungsgrenzen. Indem auf der Textoberfläche eine drei-

${ }^{103}$ Wiederum sind Vorleistungen Frauenlobs nicht zu übersehen. Vgl. DiETRICH HuSCHENBETT: Literarische Modelle zur Bewältigung der Gegenwart. Zu Frauenlobs Artus-Sprüchen. Wolfram-Studien 10 (1988) 190-206.

${ }^{104} \mathrm{Vgl}$. dazu zuletzt die Einleitung von AlBRECHT HAUSMANN sowie die Beiträge v.a. von JaN-DiRK MÜller und HaRAld Haferland in: Text und Handeln. Zum kommunikativen Ort von Minnesang und antiker Lyrik. Hg. von ALBRECHT HAUSMANN. Heidelberg 2004. 
stellige Konstellation in eine zweistellige überführt wird, wird die sangspruchtypische Ausrichtung der eigenen Rede auf ein Publikumskollektiv von >Mehreren< von einer textinternen Sprechsituation vertrauter Zweisamkeit abgelöst. Der zusätzliche Einsatz der direkten Rede der Gepriesenen/Geliebten - wobei auch dieses Gestaltungsmittel noch aus den frühen Meisterliedern des 14. Jahrhunderts bezogen werden konnte - kann den Eindruck, daß dies in der Tat die eigentliche pragmatische Kommunikationssituation sei, in die der Text hineingesprochen worden sei, noch verstärken. Unter diesen Voraussetzungen kann sich das spätere Meisterlied dem Liederbuchlied bisweilen sehr weit annähern. Das geschieht wesentlich über eine Abblendung textueller Bezüge auf ein Allgemeines: durch Verzicht darauf, eine Gemeinschaft von (männlichen wie weiblichen) Zuhörern anzusprechen, aber auch durch Verzicht der Verallgemeinerung des subjektiven Preises der Einen zum Lob des weiblichen Geschlechts insgesamt.

6. Der »Komplex >anonymes meisterliches Lied< [bildet] einen Abschnitt von erheblicher Bedeutung in der Geschichte der Gattung «: so KARL STACKMANN 1999. ${ }^{105}$ Denn: »Auf der Grundlage einer von professionellen Dichtern geschaffenen Gattung « formiere sich »ein literarisches Interesse in Schichten der städtischen Bevölkerung, die vermutlich gerade erst alphabetisiert und sogleich für die Teilnahme an anspruchsvollerer Dichtung gewonnen waren. Die Rezeption und Umgestaltung der alten Gattung stellt einen wichtigen Schritt dar in Richtung auf die Bildung eines literarischen Publikums außerhalb der Höfe. ${ }^{106}$ Die Strophen und Lieder in Sangspruchtönen Regenbogens zum Thema Minne lassen einen bedeutsamen Zwischenschritt sichtbar werden: eine überaus produktive späthöfische Frühphase des im Werden begriffenen meisterlichen Liedes von eigener Signatur, von der sich eine spätere, aber noch vor der Institutionalisierung des Meistergesangs im ausgehenden 15. Jahrhundert angesiedelte Liedproduktion durchaus absetzen läßt. Eine genauere Kenntnis dieser Frühphase wird den gesamten Systemwandel der lyrischen Gattungen im 14. und 15. Jahrhundert weitergehend erhellen. Praktisch zu erreichen ist sie am ehesten über weitere, sinnvoll angelegte Querschnitte durch das anonym überlieferte Liedgut - doch selbst dann auch nur, wenn man, statt Fremdtonverwendung implizit, von ahistorischen Originalitätsvorstellungen geleitet, pauschal als Signum minderwertiger Liedproduktion zu betrachten, systematischer zwischen anspruchsloseren Fremdtonver-

\footnotetext{
${ }^{105}$ STACKMANN [Anm. 3], S. 198.

${ }^{106}$ STACKMANN [Anm. 3], S. 199.
} 
wendern als >Trittbrettfahren spruch auftretenden Nachsängern, die gerade diese Spätphase dominieren, zu unterscheiden bereit ist. Dann aber wird man auch der Einschränkung STACKMANNs nicht zustimmen, selbst die Bedeutsamkeit des Übergangs des Sangspruchs vom Hof in die Stadt könne eine weitergehende Erschließung des meisterlichen Liedes über das insbesondere mit dem Repertorium bereits Geleistete hinaus kaum rechtfertigen, da die Texte »denn doch weit ab von der großen Literatur « stünden. ${ }^{107}$ Da sich literarische Qualität nach historisch veränderlichen Maßstäben bemißt, fordert zumal heute nur noch befremdlich erscheinender literarischer Erfolg - etwa der in der Regenbogen-Überlieferung besonders breit sich niederschlagende der anonymen Nachsänger - desto dringlicher zur Bildung neuer Analysekategorien und Erklärungsmodelle auf, die uns heute selbstverständlich Gewordenes weitergehend relativieren.

${ }^{107}$ Ebd. 


\section{ANHANG}

\section{1. Übersicht über das Textkorpus}

\subsection{Texte und Töne}

In Spalte 1 erscheint die RSM-Nummer, wobei die Strophenanzahl jeweils in angehängter Hochziffer ergänzt ist. In Spalte 2 ist die Hauptüberlieferung mitsamt in ihrer Strophenordnung übereinstimmenden Parallelen aufgeführt. In Spalte 3 wird weitere Überlieferung von variierender Strophenordnung ausgewiesen. Spalte 4 benennt die benutzten Ausgaben/Abdrucke.

\subsubsection{Briefweise}

\begin{tabular}{|c|c|c|c|}
\hline${ }^{1} \operatorname{Regb} / 1 / 5^{1}$ & C $381^{v}$ & - & $\begin{array}{l}\text { VON DER HAGEN [Anm. 15], } \\
\text { Bd. } 2 \text {, S. } 309 \text { u.ö. }\end{array}$ \\
\hline${ }^{\prime} \operatorname{Regb} / 1 / 101^{2}$ (frgm.) & $v 245^{r}$ & - & $\begin{array}{l}\text { SCHRÖDER [Anm. 2], S. } 192 \mathrm{f} \text {. } \\
\text { u.ö. }\end{array}$ \\
\hline${ }^{\prime} \operatorname{Regb} / 1 / 104 a^{3}$ & $\begin{array}{l}\text { Berlin Mgq } 795 \text {, } \\
\text { Bl. } 5^{r}\end{array}$ & $3=w 136^{3}, 1$ & $\begin{array}{l}\text { SCHRÖDER [Anm. 2], S. 193f. } \\
\text { u.ö. }\end{array}$ \\
\hline${ }^{\prime} \operatorname{Regb} / 1 / 502 \mathrm{a}^{9}$ & k 256 & $\begin{array}{l}1-6.7 .9=\text { Drucke } \\
\text { Nr. } 125 a-h^{9}, 1-6+8.9\end{array}$ & $\begin{array}{l}\text { BARTSCH [Anm. 17], } \\
\text { Nr. } 55 \text { u.ö. }\end{array}$ \\
\hline${ }^{1} \operatorname{Reg} b / 1 / 509^{3}$ & k 263 & - & BARTSCH [Anm. 17], Nr. 58 \\
\hline${ }^{1} \mathrm{Regb} / 1 / 510 \mathrm{a}^{7}$ & k 264 & $7=w 136^{3}, 3$ & BARTSCH [Anm. 17], Nr. 59 \\
\hline${ }^{1} \mathrm{Regb} / 1 / 511^{3}$ & k 265 & - & BARTSCH [Anm. 17], Nr. 60 \\
\hline${ }^{1} \operatorname{Regb} / 1 / 512 a^{23}$ & k 266 & $\begin{array}{l}3.5 .4 .6 .7 .20 .13= \\
\text { w } 74^{9}, 1-7\end{array}$ & $\begin{array}{l}\text { BARTSCH [Anm.17], } \\
\text { Nr. } 61 \text { u.ö. }\end{array}$ \\
\hline${ }^{1} \operatorname{Reg} b / 1 / 521 a b^{3}$ & k $275 ;$ k 296 & - & $\begin{array}{l}\text { BARTSCH [Anm. 17], Nr. } 65 \\
\text { u.ö. }\end{array}$ \\
\hline${ }^{\prime} \operatorname{Regb} / 1 / 527 \mathrm{ab}^{7}$ & $\begin{array}{l}\text { k } 281 \text {; Hamburg } \\
\text { germ. } 6 \text {, p. } 4-6\end{array}$ & - & $\begin{array}{l}\text { BARTSCH [Anm. 17], } \\
\text { Nr. } 69 \text { u.ö. }\end{array}$ \\
\hline${ }^{1} \operatorname{Regb} / 1 / 539^{5}$ & k 293 & - & BARTSCH [Anm. 17], Nr. 72 \\
\hline${ }^{1} \operatorname{Regb} / 1 / 541^{5}$ & k 295 & - & BARTSCH [Anm. 17], Nr. 73 \\
\hline${ }^{1} \operatorname{Regb} / 1 / 544^{3}$ & k 298 & - & Schulz [Anm. 2], S. 59f. \\
\hline${ }^{1} \operatorname{Regb} / 1 / 545 \mathrm{a}-\mathrm{e}^{3}$ & $\begin{array}{l}\text { k } 299 ; \text { Drucke } \\
\text { Nr. } 67 \mathrm{a} / \mathrm{I}+67 \mathrm{~b} / \mathrm{Il}\end{array}$ & $\begin{array}{l}1=\text { Heidelberg Cpg } \\
\text { 5, Bl. } 68^{\mathrm{v}}, 1\end{array}$ & $\begin{array}{l}\text { BARTSCH [Anm. 17], } \\
\text { Nr. } 74\end{array}$ \\
\hline${ }^{1} \operatorname{Regb} / 1 / 553^{7}$ & b 39 & - & s.u. Anhang 2 \\
\hline${ }^{1} \mathrm{Regb} / 1 / 554 \mathrm{ab}^{7}$ & $\begin{array}{l}\text { b } 41 \text {; Drucke Nr. } \\
64 a+b\end{array}$ & - & $\begin{array}{l}\text { BARTSCH [Anm. 84], } \\
\text { S. 291-294 }\end{array}$ \\
\hline${ }^{1} \mathrm{Regb} / 1 / 561^{3}$ & $\begin{array}{l}\text { Berlin Mgo } 186 \text {, } \\
\text { Bl. } 66^{v}-67^{v}\end{array}$ & - & $\begin{array}{l}\text { VON DER HAGEN [Anm. 15], } \\
\text { Bd. } 3 \text {, S. } 452 \mathrm{f} \text {. }\end{array}$ \\
\hline${ }^{1} \operatorname{Regb} / 1 / 562^{3}$ & $\begin{array}{l}\text { Wien s.n. } 3344 \text {, } \\
\text { B1. } 113^{\text {rv }}\end{array}$ & & s.u. Anhang 2 \\
\hline
\end{tabular}

${ }^{108} \mathrm{Vgl}$. hier sowie im folgenden an den entsprechenden Stellen die weitergehenden Angaben im RSM. 


\begin{tabular}{|c|c|c|c|}
\hline${ }^{1} \operatorname{Regb} / 1 / 563^{3}$ & $\begin{array}{l}\text { München } \\
\text { Cgm } 811 \text {, Bl. } 48\end{array}$ & $\begin{array}{c}- \\
49^{2}\end{array}$ & $\begin{array}{l}\text { BOLTE [Anm. 93], } \\
\text { S. } 76 \mathrm{f} \text {. }\end{array}$ \\
\hline${ }^{1} \operatorname{Reg} b / 1 / 565 a b^{3}$ & \multicolumn{2}{|c|}{$\begin{array}{l}\text { w } 135 \text {; Druck } \\
\text { Nr. } 156\end{array}$} & $\begin{array}{l}\text { ZINGERLE [Anm. 88], S. } 351 \text { f. } \\
\text { (Str. 1); Str. 2f. s.u. Anhang } 2\end{array}$ \\
\hline 'Regb/1/566a ${ }^{3}$ & w 136 & $\begin{array}{l}1=\text { Berlin Mgq } 795 \\
\text { Bl. } 5^{\mathrm{r} 3}, 3 ; 3=\mathrm{k} 264^{7}, 7\end{array}$ & s.u. Anhang 2 \\
\hline${ }^{1} \operatorname{Regb} / 1 / 567^{7}$ & h 83 & - & SCHULZ [Anm. 2], S. 41-43 \\
\hline 'Regb/1/5685 & q 255 & - & SchULz [Anm. 2], S. 94f. \\
\hline 'Regb/1/572 ${ }^{3}$ & Druck Nr. 40 & - & $\begin{array}{l}\text { VON DER HAGEN [Anm. 15], } \\
\text { Bd. } 4 \text {, S. } 635 \text { f. Anm. } 7\end{array}$ \\
\hline 'Regb/1/573 & Druck Nr. 123 & - & s.u. Anhang 2 \\
\hline \multicolumn{4}{|c|}{ 1.1.2 Grauer Ton } \\
\hline${ }^{1} \operatorname{Regb} / 2 / 31 \mathrm{a}^{7}$ & k 341 & $1.4=\mathrm{k} 343^{3}, 1.3$ & SCHULZ [Anm. 2], S. 61-63 \\
\hline${ }^{1} \operatorname{Reg} b / 2 / 33 a^{3}$ & k 343 & $1.3=\mathrm{k} 341^{7}, 1.4$ & SchULz [Anm. 2], S. 64f. \\
\hline${ }^{1} \operatorname{Regb} / 2 / 4 \mathrm{la}^{\prime}$ (frgm.) & k $361 \mathrm{a}$ & $\begin{array}{l}1=\text { Wien s.n. } 3344 \text {, } \\
\text { B1. } 108^{r 3}, 1\end{array}$ & s.u. Anhang 2 \\
\hline${ }^{1} \operatorname{Reg} b / 2 / 55 a^{3}$ & $\begin{array}{l}\text { Wien s.n. } \\
3344 \text {, B1. } 108^{r}\end{array}$ & $1=\mathrm{k} 361 \mathrm{a}^{1}$ (frgm.) & s.u. Anhang 2 \\
\hline
\end{tabular}

\subsubsection{Grundweise/Kurzer Ton/Paratweise}

${ }^{1} \operatorname{Regb} / 3 / 6^{3}$

${ }^{\prime} \operatorname{Regb} / 3 / 15^{3}$

k 452

p 38

\subsubsection{Langer Ton}

\begin{tabular}{|c|c|c|c|}
\hline 'Regb/4/508 $a^{3}$ & k 358 & $2=f 86^{3}, 1$ & BARTSCH [Anm. 17], Nr. 81 \\
\hline${ }^{1} \operatorname{Regb} / 4 / 509^{3}$ & k 359 & - & $\begin{array}{l}\text { PETZSCH [Anm. 70], } \\
\text { S. 344-347 }\end{array}$ \\
\hline 'Regb/4/563a $\mathrm{a}^{3}$ & k 414 & $\begin{array}{l}2.3=\mathrm{k} 438^{5}, 5.4 ; 2 \\
=\mathrm{w} 149^{3}, \mathrm{I}\end{array}$ & $\begin{array}{l}\text { SCHULZ [Anm. 2], } \\
\text { S. 66f. }\end{array}$ \\
\hline${ }^{1} \operatorname{Regb} / 4 / 589 \mathrm{a}^{5}$ & k 438 & $\begin{array}{l}3.5=w 149^{3}, 2.1 ; 4.5 \\
=k 414^{3}, 3.2\end{array}$ & $\begin{array}{l}\text { SCHULZ [Anm. 2], } \\
\text { S. 68-70 }\end{array}$ \\
\hline${ }^{\prime} \operatorname{Regb} / 4 / 617 \mathrm{a}^{3}$ & f 86 & $1=\mathrm{k} 358^{3}, 2$ & $\begin{array}{l}\text { VON DER HAGEN [Anm. 15], } \\
\text { Bd. } 3 \text {, S. } 468 \mathrm{k}\end{array}$ \\
\hline 'Regb/4/621 $\mathrm{a}^{3}$ & w 149 & $\begin{array}{l}1.2=\mathrm{k} 438^{5}, 5.3 ; 1 \\
=\mathrm{k} 414^{3}, 2\end{array}$ & $\begin{array}{l}\text { Schulz [Anm. 2], } \\
\text { S. } 109 \mathrm{f} \text {. }\end{array}$ \\
\hline${ }^{1} \operatorname{Regb} / 4 / 656^{5}$ & q 245 & - & s.u. Anhang 2 \\
\hline
\end{tabular}

ScHuLZ [Anm. 2], S. 71 WUNDERLE [Anm. 2], S. 193f. u.ö. 
1.2 Handschriften und Drucke

1.2.1 Altüberlieferung (bis zur Mitte des 14. Jahrhunderts)

C Heidelberg, UB, Cpg 848 (, Große Heidelberger oder Manessische Liederhandschrift<; vgl. RSM, Bd. 1, S. 178f.

v Vorau, StiB, Cod. 401 (Frauenlob-v; vgl. RSM, Bd. 1, S. 262)

1.2.2 Handschriften vom Rande der meisterlichen Tradition

Berlin, SBB-PK, Mgq 795 (>Mösersches Fragment<; vgl. RSM, Bd. 1, S. 89)

Berlin, SBB-PK, Mgo 186 (`Livländische Sammlung‘; vgl. RSM, Bd. 1, S. 91)

Hamburg, SUB, Cod. germ. 6 (`Parzival<-Handschrift G ${ }^{\sigma}$; vgl. RSM, Bd. 1, S. 169f.)

Heidelberg, UB, Cpg 5 (vgl. RSM, Bd. 1, S. 170)

München, BSB, Cgm 811 (`Liederbuch des Jacob Käbitz; vgl. RSM, Bd. 1, S. 202)

f Weimar, HAAB, Q 564 (»Weimarer Liederhandschrift<; vgl. RSM Bd. 1, S. 273)

Wien, ÖNB, Cod. s.n. 3344 (>Liebhard Eghenvelders Liederbuch‘; vgl. RSM, Bd. 1, S. 298f.)

\subsubsection{Meisterliederhandschriften}

b Basel, UB, Cod. O IV 28 (vgl. RSM, Bd. 1, S. 75f.)

h Heidelberg, UB, Cpg 392 (vgl. RSM, Bd. 1, S. 176)

k München, BSB, Cgm 4997 (〉Kolmarer Liederhandschrift<; vgl. RSM, Bd. 1, S. 205-209)

p Heidelberg, UB, Cpg 680 (vgl. RSM, Bd. 1, S. 177)

q Berlin, SBB-PK, Mgq 414 (`Naglerscher Meisterliedercodex<; vgl. RSM, Bd. 1, S. 84-86)

w München, BSB, Cgm 5198 („Wiltener Handschrift<; vgl. RSM, Bd. 1, S. 213f.)

\subsubsection{Drucke (nach RSM-Nummern)}

Nr. 40 [Augsburg um 1525] (vgl. RSM, Bd. 1, S. 348)

Nr. 64a [Straßburg] 1500 (vgl. RSM, Bd. 1, S. 358)

Nr. 64b Straßburg [1517] (vgl. RSM, Bd. 1, S. 358)

Nr. 67a/I [Straßburg, um 1545] (vgl. RSM, Bd. 1, S. 358f.)

Nr. 67b/II Straßburg [o. J.] (vgl. RSM, Bd. 1, S. 359)

Nr. 123 Erfurt 1529 (vgl. RSM, Bd. 1, S. 385)

Nr. 125a-h [Nürnberg, Straßburg, Straubing und Bern in den Jahren 1528-61] (vgl. RSM, Bd. 1, S. 385f.) 
Nr. 156 [Würzburg um 1500] (vgl. RSM, Bd. 1, S. 407)

\section{Abdrucke bisher unedierter Texte}

Diakritische Zeichen werden, wo nicht wirklich eindeutig zu identifizieren, mit zwei hochgestellten Pünktchen wiedergegeben. Zeichen über $\langle y\rangle$ werden allerdings nicht wiedergegeben, ebensowenig über $\langle u\rangle /\langle v\rangle$, wo sie nur den vokalischen Lautwert markieren sollen. Die Groß- und Kleinschreibung ist vereinheitlicht: nur Eigennamen werden systematisch groß geschrieben, und nur Strophen und Strophenbausteine beginnen mit Großbuchstaben. Die Strophengliederung wird durch Absätze verdeutlicht. Die Verse sind abgesetzt. Als Lesehilfe wird eine Interpunktion eingeführt.

$2.1>$ Got grüss dich lieb, gott grúss dich zart< - sieben Strophen in der Briefweise Regenbogens ( $\left.{ }^{1} \operatorname{Regb} / 1 / 553\right)$ aus der Baseler Meisterliederhandschrift (b 39)

$\left[B l .41^{\prime}\right]$ Siben lied in der brieff wiß

[I.]

Got grúss dich, lieb, gott grüss dich, zart, got grùss dich, fin.

gott grúss dich, herczen lieber schóne bůle min.

gott grưss dich von dem hobet uff die füsse din.

gott grüss dich, lieb, zů aller stund, den abe \{n $\nmid$ vnd den morgen.

Gott grúss min lieb, das ich in minem herczen hon.

gott grüss dich, lieb. ich schlaff, ich wach, ich sicz, ich ston, gott grúss dich, lieb, von dir so mag ich nit gelon.

gott grüss dich, lieb, min lieb in lieb hon ich zů dir verborgen.

Ach liebes lieb, kuind ich den tag geleben, das ich dir mócht min liebin also gar herclagen, von minem anfang an das ende gar gesagen.

die wil das nit geschicht, so ist mir sin vnd mùt herschlagen.

gott gruss dich, lieb, din treuwen rat so 1 tht du mir dar inn geben.

[II.]

Min lieb, diu sprach: >du kanst mich wol hermanon hart, vnd haust din sủssu red ouch nit an mir gespart.

es hilft dich nit, du můst hin uff ain andru fart.<

er sprach: >owe, min schónes lieb, můss ich din urlob haben?

Siu sprach: >asta, vnd kanstu denn nit schimpff verston?

man sol an rettlich dochter sich versprechen lon.

von ainem straich so fellet nit an grosser bon.

das sing ich jungen lüten vor vnd ler die selben knaben.

Si dir an lieb in dinem mùt gefallen, so schlich ir nach, vnd důs doch in haimlickait, vnd mach den wandel vor der welte nit zu brait: so kumpt an stund, das siu dir lechten nit versait. vnd hưtt dich vor der welt gesicht vnd irem falschen kallen! 
[III.]

Es kumpt wol dick, das aim an gůtes hail beschech, vnd $\left[42^{\prime}\right]$ das an falsches oug nit sinen wandel sech, vnd das ain falschon zung nit liegen dar zů iech.

so mo̊cht es im nit nůsse gon, vnd wer sin fro̊d attsprungen.

Von falscher zung tůn ich euch hie sagen kund:

ain falschu zung machat meings vngesund, ain falschu zung tůt eben as ain vogel hund, siu louffet uff der lůgi spor gen alten vnd gen jungen.

Diu zung statt an das falsche hercz gebunden, an falsches hercz, darinn der falsch verborgen lijt. diu zung, diu redet nit wenn was das hercze git. der túfel schiss doch in ain falsches mule wijt vnd tail die zung, hercz vnde lung, dar sinen helle hunden.

[IV.]

Es kumpt wol dick, was ainr ain iar herwe \{r ben kan. ain falschon klafferin, diu macht sich uff die ban; siu spricht zu sinem lieb: >ich dir des güten gan. nit ker dich an den armen knecht, er hatt nit vor der hứte.

Vnd stell nach Kainczen, maigers sůn, der sels hatt wol. nach dem richen man gar billich stellen sol. win vnde korn sin kasten sind im elle vol. da finstu hab vnd rates fil, das du haust as ander lúte.<

Die dochter ward der zwifel vme iagen. siu gieng zum dancz vnd sach irn lieben bůlen fin. da sto̊nd des buren sun dơrt rubon as an schwin. siu sprach: >du clafferin, nůn lauss din claffon $\sin$ ! vnd retstu v๋mer wort dar zů, ich wils mim bůlen sagen.<

[V.]

Da nůn diu clafferin herhort der dochter sin, da luff siu bald zu irem lieben vatter hin. siu sprach: >a, hơra, merka, lieber nachbor min: din dochter, diu will ije an weg mit ainem armen bủben.<

Siu sprach: > vnd hilffstur nit gar in ainr kurczon frist, siu macht ain nest vnd let er selber uff den mist. ich sag dir wol, das Kainczen sůn ir weger ist. man git im ecker, wison vil, vnd ouch der maiger hůben.

Der man was bald nach siner dochter schicken. $\left[42^{v}\right]$ er sprach: $>\min$ kint, was wit du vnderwinden dich? du sottust vmm ain sơlichs billich fragon mich. ich sag dir wol, für was ich vnverholen sprich: vnd niemstu dir den armen knecht, du můst bij im hersticken.< 
[VI.]

Siu sprach: >das schat nit herczen lieber vatter zart. mir kam des buren sun ouch hiut an miner fart. er hett an můs geklaibet da an sinem bart, vnd hett sich mit der milch betrofft recht sam die schnecken schliffen.

Er hett an bschissen iuppen an, uff mine trew, vnd hett zwen grose stifel an.< aso rett siu: >durch ijeden stifel gieng im da das sine knew. dar uff der mist ains iares alt. sôtt ich in ane griffen?

Dess buren sủn, des sott du mich herlaussen. gib mir den bůlen, den ich in minem herczen hon. der trett sin hobt, dar uff sin har gebúrstot schon, sin hoson schlecht, vnd sinen gưrtel wol geton. den nem ich für dess maigers gůt. er liebt mir vne mausse!

[VII.]

Der vatter sprach: >du wit ije haben dine wis. vertůstu ains, wa niemstu denn ain ander spis?< siu sprach: >da beratt mich lechten gott der alte gris, der allen schacz verborgen hatt in siner milten hende.

Gott ist der maiger. der sol mir ein zůgelt geben. uff sin gnad, so will ich tegelichen leben, vnd will ouch wider hin zů minem bůlen streben.< siu nam in czů der stetickait bis gar an ire ende.

Vnd sött man sich armer allen wegen weren? sich gott, wie wúrdes vmm die armen denn getan? menger ist rich vnd wurt an armer gókel man. der arm wurt rich. gott alles das gefugen kan. ich nem glúck fur alles gůt, will mir es got bescheren.

2.2 Wol hin vnd der mit lieb wil fleissen seine tag « - fünf Strophen in der Briefweise Regenbogens ( $\left.{ }^{\prime} \operatorname{Regb} / 1 / 562\right)$ aus $>$ Liebhard Eghenvelders Liederbuch<

[Bl. $\left.113^{r b}\right]$ Tagweis

[I.]

Wol hin, vnd der mit lieb wil fleissen seine tag, der mag wol trawern lassen vnd sein sende chlag. ich main, das nyme sein laid mit ganczem willen trag. dy selbig $\left[113^{v a}\right]$ nat gewirret mir; ich trag mein not nit gerne.

Sich hat ein fraw versert in meines herczen grunt. si tuet mir laid, nach liebt si mir zu aller stund. si tregt zway liechte wenglein vnd einen rosenvarben mund, darob zway gespilte ewglein chlar: das sind mein morgen sterne.

[repetitio] Wolt got, solt ich an iren zwain weissen arm ruen 
dise winder lange nacht vncz an den tag.

ach herre got, das mich mein wunschen nit gehelfen mag!

das ich der lieben nit gedienet hab, ist mir ein slach.

welt ie mich frau verderben lan, das mocht wal got erparmen.

[II.]

Die mynichleich, die sprach >dein red ist guet<

vnd sdaz mich got behuett vor aines zagen mannes muet.

ich han mein er so so lang vnd auch so wol behuet, vnd wurd ich einem schalk ze tail, das müst mich ymmer rewen.

All erst so muest ich chlagen vnd bewainen meine laid.

ach herre got, nu fueg mir ain, der mit eren sey bechlait.

vnd ist er mir beschaffen, so pin ich ym berait

in ganczer lieb, mit stetichait vindt er niemen trewen.

Ich geb nu einem stolczen leib, des er begert.

wes er da muett, des ist er von mir gewert.

so wurd sein stete frewd, vnd auch die mein gemert.

so redt die rain gar tugentleich. mein trawern, das wer chlaine.

[III.]

Ach frewlein czart, du preingst mich gar in sendes laid.

vernym mich, herczen lieb. was ich dir vormals hab gesait, des pis gewis, vnd trag gein mir dein stetichait, ach schone fraw, ein churcze frist, das sich mein laid nit meret.

Ich sach bey niemen tagen nie kain schoners weib, vnd das mir pas geuiel, dann, fraw, dein stolczer leib.

du pist meins herczen wol ein hoch stecz laid vertreib.

ach schone fraw, ge $\left[113^{v b}\right]$ denk dar an: ich mag dein nit enperen.

Wolt got, das ich der schonen frawen liebet, so hulf si mir hewt vnd ymmer aus sender nat.

ach frewlein zart, was peutet mit dein mundlein rot?

ob mir engieng, so muest ich ymmer sterben tot.

die redt soltu gelauben mir. ich redts an allen scherczen.

[IV.]

Dy rain, die mynichleich, die sprach: sgot geb euch hail.

ich main, das dir mein stolczer leib nit werd ze tail, den ich so lang behalden hab wol vor der schandten ein mail.

du pist ein kind, das wais ich wol. ich tar dir nit getrawen.

Wie woldestu in eren einer steten frawen phlegen?

wer hiet dir die synn vnd auch die wicze geben?

ich wil dir raten, lass vnder wegen,

das du dich vnder winden wolts nür einer steten frawen.

$\mathrm{Nu}$ bleib allain, pis du dich pas besinnest, piss du derkennest payde ubel vnde guet.

aller erst so merk, wo ein fraw so frewntleich gegen dir tuet, 
so der dich ker, vnd trag sey stet in deinem muet, vnd hab sey lieb fuer alle weib: so mag dir wol gelingen.s

[V.]

Do mir die lieb zum aller ersten wart erkant, do vand ich si, da si mir ein chrenczlein pand von plaben pluemen, stetleich in mein hercz gesant. da bey mag ich ir vergessen nit. das pringt mir lieb vnd laide.

Ach frawlein zart, was welt ir meinen jungen zeit, vnd ob mir got die synn vnd auch die wicze geit, das ich ewr wol mit eren phleg, dar an euch wol genueget.

>Ach junger man, ich wil in ewr genade treten.

ir seit gewert, wes ir habt vormals lang gepeten.<

der chnab, der sprach: >ich dank euch gernn, ich lab ewr beibleich guete.<

2.3 >Ich hab jn meinen sinnen das $<$ - drei Strophen in der Briefweise Regenbogens ( $\left.{ }^{1} \mathrm{Regb} / 1 / 565 \mathrm{a}\right)$ aus der $>$ Wiltener Handschrift< (w 135)

$\left[B l .140^{v}\right]$ Regenpogen iij lied in der brief weis ain mans lob [I.]

[vgl. für Str. I den Abdruck bei ZINGERLE (Anm. 88), S. 351f.]

[II.]

[141']

Got hat die werden man erhöcht gar wirdigkleich, wann hie auf erd zu mannes hant stend alle reich: darvmb ist weybes nam der manheyt vngeleich.

got gab den mannen den gewalt das sy vergeben sunde.

Die werden man erwerben vmb den zarten got, das er von hymel kumbt herab durch jr gepot. er lat sich nyessen willigklich an allen spot ze trost der armen cristenhayt. der hab wir ym urkhunde.

Jch main die priester, die da got empfahen. darvmb ist weybes nam der manhait vngelegenn. jn mannes hanndt, so lät sich schauen der höchste degen. da er gen hymel für, da gab er vns den segen mit mannes hant, das laut euch rainen frauen nit verschmachenn.

[III.]

Was jn der heyligen kristenhayt ye stet geschriben, das haben die man erdacht, vnd also ist beliben. ich sprech fur war, es wirt auch nymmermer vertriben. das wollent vnns die werden mann gar aygentlich bewaren.

All propheten, vnd die heyligenn peychtiger, das warn alles man, vnd hettn grosses schwer. 
die heyligen zwelfpottn kunden vnns die mer,

das vnns die mann die cristenhayt vergulden vnd erklären.

Jr werden frawen, jr solt davon gedengkhen,

seyt das die man so gar manleichen haben gethan,

ain werder man, der wolt durch forchte nicht entlan:

er wolt für alle sünder jn die marter gan.

$\left[B l .141^{\mathrm{V}}\right]$ sein grosse kraft durch sein manhayt sach man da nyndert wengkhen.

$2.4>$ Ich han jn meinem synn erdacht $<-$ drei Strophen in der Briefweise Regenbogens ( $\left.{ }^{1} \mathrm{Regb} / 1 / 566 \mathrm{a}\right)$ aus der $>$ Wiltener Handschrift<

(w 136)

$\left[\mathrm{Bl} .141^{\mathrm{V}}\right]$ Frawen lob hat gemacht die nachgeschribn iij lied jm brief don von frawen

[I.]

[vgl. für Str. 1 die für die Parallelüberlieferung in 'Regb/1/104a,3 im RSM ausgewiesenen Ausgaben/Abdrucke]

[II.]

Ich frag dich, weyb, ob dw doch selb erkennest dich:

wer dw pist, vnd von wann dw kumbst, beschayde mich

durch deinen werden namen sag / $/$ an vnde sprich.

sy sprach: >jch pin dein fleisch vnd pluet, dein weltlich freud vnd wünne.

Wann ich bin auch gemacht also dw, das wiß alsuß.

got selber dir ain rippe prach aus deiner prust.

davon mein hercz sich senen thuet jn solichem glust,

gedengket an das hercze dein, die rippe durch das künne.

$\left[142^{r}\right]$ ich bin von deiner saytes pluet entsprungen

vnd bin die frucht, die deines leybs verch gepar.

darzw so bin ich hübbsch vnd guet, vnd darzw klar,

darzw manklichem pild vil freuden offenbar,

vnd dabey guet geselschaft. dar swechenn menschlich zungen.<

[III.]

[vgl. für Str. 3 die für die Parallelüberlieferung in 'Regb/1/5104a,7 im RSM ausgewiesenen Ausgaben/Abdrucke]

2.5 >Iunckfrawlein zart, ewer lieb mich seer anfacht < - drei Strophen in der Briefweise Regenbogens ( ${ }^{1}$ Regb/1/573) aus Druck Nr. 123 (Erfurt, [Matthes Maler], 1529)

$\left[B l .3^{r}\right]$ Eyn ander lied 


\section{[1.]}

Iunckfrawlein zart, ewer lieb mich seer anfacht. iunckfrawleinn zart, von rosen hab ich mir erdacht, iunckfrawlein zart, darauß ich mir ein krentzlein flacht. yr seit ein roß ob allen iunckfrawen reyn: des last euch nicht verdriessen.

Der ware gott, der wol euch senden seinenn segenn. der engel gottes wol ewer zcu allenn zeytenn pflegen. iunckfrawleinn zart, alles traurenn last mir vndter wegen. alles geluck vnnd alles hayl, das laß euch got entsprissen.

Ewer mundtleinn rot hat mir mein hertz besessen. iunckfrawleinn zart, ich bin gebunden an ein band. iunckfraw $\left[3^{v}\right]$ lein zart, mein leben stat yn ewer handt. iunckfrawlein, do ich euch ersach, mein laydt, das verschwandt. des gieb ich euch die trawe meinn: ich kan ewer nit vergessen.

[II.]

Der euch an sicht, vnd der ist ein selig man. ich sprich furwar, vnd wemm die zarte guttes gann. iunckfrawleinn zart, wen ich bey ewern gnaden thun stan, ewer freundtschafft vnnd ewer zarter leib kan mir wol trawren schwechen.

Junckfrawleinn zart, wenn ich des morgens frue auff thunn stann, iunckfrawlein zart, so wil ich yn ewer gnaden gan. iunckfrawlein zart, mit dinst binn (ich) euch vnderthon. ewer tugenthafftiger rotter mundt kan tugentlichen lachen.

Ein krentzlein grun wardt mir von euch gesendet: das selb wil ich fur alle schone iunckfrawenn tragenn. iunckfrewlein zart, ewer tugent sol mir nichts versagenn. iunckfrawlein zart, szo wil ichs frolich mit euch wagen. yhr seidt $\left[4^{r}\right]$ meyn hochster wan vmb euch stee ich elende.

[III.]

Vnnd das alle schone iunckfrawen lebten syder Adams zeyt, vnnd die da waren yhn der welt so weit vnnd der klare sunnen schein auch vberscheinndt -

Absolon wardt nie so schon, ehr mocht euch nit geleichen.

Keyn schoner engel ist nit yhn dem paradeyß.

ewer hendtleinn zart, ewer prustlein, die seyndt also weyß. iunckfrewlein zart, dar auff da legt ich meinen vleyß, ich bin euch vonn gantzem meym hertzen holdt: ewer scho̊nn ist gar

Jch lob euch fur die sunnen, monn, vnd auch die stern, [miniglichen. ich lob euch fur die liechten, klaren karfunckel stein. iunckfrewleynn zart, in rechter trew ich das mayn: yr seidt meynes hertzen wol eyn kayserinn. alde, schons lyeb, myt guter nacht! bey euch, da wer ich gern. 
2.6 Wjp edler stam, wip reyner hort< - eine unvollständig aufgenommene und dann durchgestrichene Strophe im Grauen Ton Regenbogens $\left({ }^{1}\right.$ Regb/2/41a) aus der $>$ Kolmarer Liederhandschrift $<~(k$ 361a)

$\left[B l .344^{r a}\right]$ Aber iij ein prys liet

[siehe unten zur Parallelüberlieferung in 'Regb/2/55a,1]

2.7 Weib edler stam, weib rainer hort - drei Strophen im Grauen Ton Regenbogens ( $\left.{ }^{\mathrm{R}} \mathrm{Regb} / 2 / 55 \mathrm{a}\right)$ aus $>$ Liebhard Eghenvelders Liederbuch

[I.]

[Bl. $108^{r a}$ ] Weib edler stam, weib rainer hart, dein lob stet hoch gemessen, vnd dich holt nyme volloben kan, du pist der tugent ein prunn, der dir enphloss vom herren Adam. weib rainer hart du edels walsam schrein.

So lab ich weib hie vnde dort: das lob haben se besessen. ich lob se fur den liechten tag, ich lob seu fur dew sunn, ich lob den iren zarten leib fur golt vnd fuer der liechten rosen schein.

Ich lob seu fur des mayen zeit, ir lob $\left[108^{r b}\right]$ nymer zergat. ich lob seu fur dy haiden prait, was pluemen darauf stat. ich lob (seu) fur der sterne glancz, ich lob seu fur die luft aus mayen lant.

[II.] secundum

So wol den man, der ein rain traut seligs weib chan treutten: der hat lust vnd freuden uil, wann er es chan besinnen. mit irer guet si in twingen chan, nacht vnd tag, nach ires herczen glust.

Dem ist pas dan chaiser reich mit lanten vnd mit leuten, wem ein frau genad wil mit irer edlein mynn. ir paider freud, die wirt so gross, wenn si in smukt so zertleich an ir prust.

[repetitio] So wenn vns dann die freud wirt chund von frauen wirdichait, darczu ir rosenuarber mund, ir mynn hat wider sait. wenn trauernn soll wir uaren lan: frau Venus furt ir payder waffenchlaid.

[III.] tertium

Weib laid vertreib, frauen breis ob aller augenwaid. du liligen suesser smach, was rosen auf der haid da fur so zesemt frau dein lob vnd balsambt schon uber alle suessichaitt.

So hort man voglein sank auf gruenem reis, was liligen in den auen. die im der may durch susset hat, da fuer lob ich die frauen. ich lob seu fur der saitten don, ir zucht, ir er ist warden praitt.

Ir mund der ist gehonigt pas wenn honigs sames chraft. ir mynn, die geit vns freuden uil ob aller maisterschaft. ir augenplick ist durch suesset pas, wenn ye cham czucker nach honigs sam. 
$2.8>\mathrm{Jr}$ reinen frawen nemet ware $<$ - fünf Strophen im Langen Ton Regenbogens ( $\left.{ }^{1} \mathrm{Regb} / 4 / 656\right)$ aus dem $>$ Naglerschen Meisterliedercodex $<(\mathrm{q} 245)$

[Bl. $\left.316^{\prime}\right]$ Regenpogen langer don 5 lieder

[I.]

$\mathrm{Jr}$ reinen frawen, nemet ware

vnd merckt einen scharpffen list, den ich kunt dun:

nach der gepurt wirt euch geseit,

die sich in manch frawen gar verdirbet.

Das wirt an mancher offenpare, wen sie gepirt, es sey ein dochter oder sun:

das plut, das ir dy selben zeit

an der matrix erfüllet vnd erstrebet,

da von die adren nit ein/Jmag

in geben luft, die zw denn prüsten streben.

sie leit vnd füllet manchen dag.

das macht dis plut ist vmb die matrix cleben.

das ist den frawen vngesunt

vnd müssen kummer dol,

wan sie sindt grosser schmerczen also vol.

$\left[316^{\prime}\right] \mathrm{Jch}$ han gelessen die figur:

eine mer dan die ander leidet pein.

welch fraw ist zornig in natur,

die mus auch lenger in dem schmerczen sein,

wan die gepurt ist manigfalt.

dar nach auch ye kein mon nit fragen sol.

sie sindt hard in den dot verwunt.

derselben frawen sol mon pflegen wol.

[II.] 2

Es dut manigem mon verschmahen, wan im sein fraw $\mathrm{zw}$ krefften pringt ein dohterlein, vnd wirt vnfro, pin ich bricht, vnd wil nit danken got aus herczen gründen.

Welche fraw zw gepurt dut nahen, palt sie got erlosset von pitterlicher pein, vnd sie menschlich pild ane sicht, an wandel par freit sie sich $\mathrm{zW}$ der stunde.

Wan sie zw rechter zeit gepirt, dar nach gar schir jr die matrix verseiget.

dem kint sein speis gesamet wirt vnd auch der muter also auf steiget. dasselb zimet der matrix wol al zw der selben zeit, 
vnd auch dy speis sie in das menstrum dreit. der flus sych ein dy prustlein lege die weis das kint sein speisse da von nimpt. das menstrum, das wirt nit erwegt, wie wol dem kind sein speisse da von zimpt. es geit in sunderleiche krafft, dar nach der frawen ir nature geit ir rechte sie nie haben sal, die weil das kindlein an den pristlein leit.

[III.] 3

Jr frawen mercket wol ein wunder, was ich sag, das dut arglichen wol sehn. in sorg gepert ir ewer kint al in dy welt mit piterlichem schmerczen.

Euer guter wil ist darvnder, das müssen mir die reinen frawen helffen jehn, ir keine das nit anders vint, dan schweren mut verporgen on dem herczen.

So mag es anderst nit gesein: vnd ob ein kint gepir ein keisserine, so mus sie selber in die pein.

das kumet als von der süssen mynne ja der man pfliget degeleich, peid, frawen vnde man, die orgeleiche in der myne ston: das schuf das aller erste weib. $\left[317^{r}\right]$ das menschlich pilt wirt pitterlich geporn. an mancher hande menschen leib ist meisterliche dreu so gar verlorn. lat mich die arbeit reyen nit. ir reinen beib, von got wirt euch der lon dort in dem werden himelreich igklicher, dy ir er beheltet schan.

[IV.] 4

Albertus, der hat vns beschriben von der haimligkeit der beiber vnd hat zalt, palt ein fraw enpfacht zw der zeit, so wirt das frawen pilt gar [Hs. gas] ser gekrencket.

Die matrix hat der kamer siben, dar inen dan das menstrum palt gesamet wirt. ir mercket alle ane leid: ir wandel, der wirt manig valt belencket.

Die matrix dan verschleuset sich. 
dar in menschlich natur kimet zw krüfften.

so mag mon wol suptiligklich

der selben frawen $\mathrm{zw}$ der (...) en luften.

hort, wie ich das bescheiden wil.

es hat ein solche kür:

man sol es geben wiczigklichen vür,

das ich offenlich kunt

den frawen, die der kinder schwanger sint.

vns sagen weisser meister munt,

die natur krenckt die frucht, das kindelein.

ich sag uns aigentlich vür bar:

weliche fraw ir kint also gepür,

die sol sich zeigen nit zw vil,

die weil geofnet sind da al ir dür.

[V.] 5

$\mathrm{O}$ wiplich pild durch dein ere,

wan dv dein heimligkeit gewinst mit ganczer macht,

so solst tus eigentlich vürwar

dein fus nit plos dir mane sehen lassen.

Dein leib den gürt dw auch nit sere.

las im den raum den dag vnd auch die gancze nacht,

pis es hin get vol kumen gar,

vnd ge nich vil zw kirchen vnd zw strassen.

Vnd dw auch zw der selben zeit

dein (...) dein haubet dw pinde.

dein plick vns selten frumen geit,

auf dans soltw nit heben junge kinde.

das selb beweist vns die geschrifft,

vnd dut vns noch mer kunt

nach der ler naturlicher meister mund:

wie menschen art entpfangen wirt,

vnd wie das samen leit in $\left[317^{v}\right]$ welcher mas,

vnd wie mons auf die werlet pirt.

von dissem menstrum vernemet das,

davon ic $(h)$ [Hs. icz] icz sag zw dem zil,

wan es kumpt von dem leib zw disser stund.

so ist es als das herbe gifft,

davon dyne lad(...) wirt entzünt. 